\title{
Parques Nacionales y la configuración de un destino turístico: transformaciones socio territoriales en San Martín de los Andes, Argentina (1937-1955)*
}

\section{Resumen}

La creación de áreas protegidas en Argentina inició a principios del siglo XX con una fuerte influencia del modelo norteamericano y se consolidó con la conformación de la Dirección de Parques Nacionales (1934). En este artículo analizamos el proceso de creación de un lugar turístico en el área de San Martín de los Andes como resultado de las intervenciones promovidas a partir del establecimiento del Parque Nacional Lanín (1937). La metodología consistió en el análisis de bibliografía especializada y fuentes de distintas procedencias: archivos de la Administración de Parques Nacionales, Censos Nacionales y de Territorios Nacionales; y guías de turismo y otras publicaciones que circularon durante el período de análisis. El inicio de la actividad turística en una región que era política y económicamente marginal trajo aparejada una dinámica de espacialización particular, destacándose el fomento de una urbanización que iba, paradójicamente, de la mano de la conservación de grandes extensiones de tierra como reservorios de una naturaleza "inalterada".

\section{Palabras clave}

Tesauro: Parques nacionales, turismo

Autor: Territorio, Patagonia.

Referencia bibliográfica para citar este artículo: Landini, Gabriela. "Parques Nacionales y la configuración de un destino turístico: transformaciones socio territoriales en San Martín de los Andes, Argentina (1937-1955)". Anuario de Historia Regional y de las Fronteras 26.1 (2021): 71-110.

Fecha de recepción: 01/07/2020

Fecha de aceptación: 23/08/2020

Gabriela Landini: especialista en Museos, Transmisión Cultural y Manejo de Colecciones Antropolígicas e Historicas, Facultad de Filosofía y Letras de la Universidad de Buenos Aires. Código ORCID: 00000001-9226-5118. Correo electrónico: gaby_landini@hotmail.com.

\footnotetext{
* Este artículo es producto de la investigación realizada para mi tesis de licenciatura en Historia, titulada Creación y posicionamiento de un destino turístico patagónico: Transformaciones socioterritoriales en la zona de San Martín de los Andes a partir de la creación del Parque Nacional Lanín (1937-1955), presentada en la Facultad de Filosofía y Letras, Universidad de Buenos Aires, 2019.
} 


\title{
National Parks and the Configuration of a Tourist Destination: Socio-Territorial Transformations in San Martín de los Andes, Argentina (1937-1955)
}

\begin{abstract}
The creation of protected areas in Argentina started at the beginning of the 20th century with a strong influence of the North American model and was consolidated with the formation of the Directorate of National Parks (1934). In this article, we analyze the process of creating a tourist place in San Martin de los Andes area as a result of the interventions promoted since the establishment of the Lanin National Park (1937). The methodology consisted of the analysis of specialized bibliography and different sources: archives of the National Parks Administration, National Censuses and National Territories Censuses; and tourism guides and other publications that circulated during the period. The start of tourist activity in a region that was politically and economically marginal, brought a particular spatialization dynamic, which included the promotion of an urbanization that went, paradoxically, hand in hand with the conservation of large areas of land as reservoirs of a "unaltered" nature.
\end{abstract}

Keywords: National Parks, Patagonia, Territory, Tourism.

\section{Parques Nacionais e a configuração de um destino turístico: transformações sócio-territoriais em San Martín de los Andes, Argentina (1937-1955)}

\section{Resumo}

A criação de áreas protegidas na Argentina começou no início do século $X X$, com forte influência do modelo norte-americano, e foi consolidada com a formação da Diretoria de Parques Nacionais (1934). Neste artigo, analisamos o processo de criação de um local turístico na área de San Martín de los Andes, como resultado das intervenções promovidas desde a criação do Parque Nacional Lanín (1937). A metodologia consistiu na análise de bibliografia especializada e fontes de diferentes fontes: arquivos da Administração de Parques Nacionais, Censos Nacionais e dos Territórios Nacionais; e guias de turismo e outras publicações que circularam durante o período analisado. O início da atividade turística em uma região política e economicamente marginal trouxe consigo uma dinâmica de espacialização particular, destacando a promoção de uma urbanização que, paradoxalmente, esteve de mãos dadas com a conservação de grandes áreas de terra como reservatórios de uma natureza inalterada.

Palavras-chave: Parques nacionais, Patagônia, território, turismo 


\section{Introducción}

La creación de áreas protegidas en Argentina adoptó el modelo pionero de parques nacionales surgido en Estados Unidos a fines del siglo XIX. ${ }^{1}$ Este origen se remonta a 1872, con la inauguración de Yellowstone, al que le siguieron una serie de parques posteriormente integrados en un sistema nacional. Los parques nacionales fueron una invención norteamericana que se explica, siguiendo a Nash, por la relación que se estableció históricamente entre esta nación y su entorno natural, particularmente en cuanto a su definición como wilderness. ${ }^{2}$ En un marco de consolidación del capitalismo industrial y avance de la urbanización en Norteamérica, se produjo una mirada nostálgica sobre la naturaleza conquistada a través de la expansión de la frontera y colonización de las tierras al oeste del continente. Desde una fundamentación centrada en la valorización de ideales democráticos unida a la preservación de un escenario fundacional de la nación, la creación del concepto de parques nacionales se centraba, discursivamente, en la preservación de ciertos lugares para uso y disfrute público. Esta conceptualización, como han demostrado diversos autores, no estaba exenta de una dimensión política e ideológica en la que se podía identificar un interés particular como "estrategia de apropiación material y conceptual del territorio". ${ }^{3}$ El modelo norteamericano de parques fue replicado internacionalmente, más rápidamente en países de características territoriales similares, como Canadá y Australia -que crearon sus propios parques desde $1879 \mathrm{y}$ 1885, respectivamente. En América Latina, la expansión del "modelo Yellowstone" ha sido estudiada críticamente por Antonio Diegues, quien destaca cómo la idea de preservar una naturaleza inalterada entró rápidamente en conflicto con la existencia de poblaciones tradicionales que habitaban esas tierras. ${ }^{4}$

En el caso argentino, la fecha temprana que se toma corresponde a la donación de tierras con el fin de ubicar el primer parque nacional en la Patagonia, proyecto que se pudo concretar oficialmente en 1922 con la creación del Parque Nacional del Sur. Sin embargo, se puede decir que su institucionalización se concretó años más tarde, con la creación de un organismo de injerencia nacional en 1934: la Dirección de Parques Nacionales. Para ese momento, las áreas andinas del norte de la Patagonia habían sido recientemente ocupadas y colonizadas por el ejército. $\mathrm{Su}$ población era considerada escasa ${ }^{5}$ y sus economías marginales, más vinculadas

\footnotetext{
${ }^{1}$ Norberto Fortunato, La civilización de las "tierras salvajes". Valores fundacionales del concepto de Parque Nacional (Buenos Aires: Prometeo Libros, 2010).

${ }^{2}$ Roderick Nash "The American Invention of Natural Parks", American Quarterly, 22.3 (John Hopkins University Press: 1970) 726-735.

${ }^{3}$ Norberto Fortunato 735 .

${ }^{4}$ Antonio C. Diegues, "El mito moderno de la naturaleza intocada" Hombre y Ambiente 57-58, Número Monográfico (Quito: Ediciones Abya Yala, 2000)

${ }^{5}$ La población preexistente a la llegada del ejército nacional se componía principalmente de comunidades indígenas instaladas en sectores estratégicos, con una movilidad que se caracterizaba por su carácter transcordillerano. La ocupación militar y el inicio de la colonización, implicó el traslado forzoso de muchos de ellos, al mismo tiempo que nuevas corrientes migratorias de criollos y extranjeros empezaban a confluir en los espacios delineados por el Estado, como fuertes, fortines o colonias agrícola-ganaderas.
} 
al mercado transandino que al nacional, orientado al Atlántico. La persistencia de una marcada integración en el espacio cordillerano es señalada por varios autores, que coinciden en presentar un territorio en el que, aún luego del trazado de límites oficiales, mantenía una dinámica regional binacional. ${ }^{6}$ En este marco, los Parques Nacionales se enmarcaban en un contexto de consolidación del control sobre ese territorio fronterizo. ${ }^{7}$ En este sentido, especialmente en el período señalado, uno de los principales objetivos de la DPN estuvo orientado a la reorientación de las economías de localidades y territorios donde se localizaban. El período de entreguerras fue un momento de crecimiento de la actividad turística en Argentina, traccionado en parte por el avance del uso del automóvil y el progresivo cierre de los mercados externos. ${ }^{8}$ Las organizaciones civiles (como el Touring Club o el Automóvil Club Argentino) fueron partícipes de la emergencia del turismo como asunto público y como recurso económico. ${ }^{9}$ La reproducción de imágenes en diferentes ámbitos de la cultura fue central para la construcción de paisajes turísticos, al mismo tiempo que se posicionaba esta práctica con un sentido patriótico..$^{10} \mathrm{El}$ creciente intervencionismo del Estado, por su parte, contribuyó mediante la ejecución de obras y generación de estructuras administrativas necesarias para poner en funcionamiento esta actividad económica.

En este marco, la instauración de los Parques Nacionales fue una de las estrategias impulsadas desde el Estado con el objetivo de "[...] integrar al turismo en la puesta en explotación productiva del territorio nacional", ${ }^{11}$ motivo por el cual Piglia la considera como un primer ensayo de política turística sistematizada. ${ }^{12} \mathrm{El}$ ejemplo más conocido de este proceso es el que se dio en San Carlos de Bariloche y su área de influencia alrededor del lago Nahuel Huapi, donde el turismo se terminó por constituir en la principal actividad económica de la localidad. Actualmente, muchas de las áreas protegidas de Argentina -como ocurre en otros países- se han consolidado como destinos turísticos nacionales.

\footnotetext{
${ }^{6}$ Susana Bandieri y otros (eds.), Historia de Neuquén (Buenos Aires, Plus Ultra, 1993).

Graciela Blanco, "Las sociedades Anónimas cruzan los Andes: los inversores chilenos en Neuquén al comenzar el siglo XX”, América Latina en la Historia Económica, 2.38 (2012): 107-130.

Laura Méndez y Jorge Muñoz Sougarret, “Alianzas sectoriales en clave regional. La Norpatagonia argentinochilena entre 1895 y 1920”, María Andrea Nicolletti y Paula Núñez (Comp.) Araucanía - Norpatagonia: la territorialidad en debate: perspectivas ambientales, culturales, sociales, políticas y económicas (Bariloche: Instituto de Investigaciones en Diversidad Cultural y Procesos de Cambio-CONICET-UNRN, 2013).

${ }^{7}$ Norberto Fortunato 735 .

${ }^{8}$ Silvia Ospital, “Turismo y territorio nacional en Argentina. Actores sociales y políticas públicas, 19201940”, Estudios Interdisciplinarios de América Latina, 16.2 (2005): 80.

${ }^{9}$ Elisa Pastoriza y Melina Piglia, “Asociaciones civiles, empresas y Estado en los orígenes del turismo argentino”, Anuario IEHS, 27 (2012): 393-415.

${ }^{10}$ Perla Zusman "El paisaje: la razón y la emoción al servicio de la práctica turística”, Rodolfo Bertoncello 199-219.

${ }^{11}$ Alejandro Capanegra, "El desarrollo turístico como estrategia política del Estado: de la política en turismo a la política turística. Argentina 1900-1975”, Aportes y Transferencias. 14.1 (2010): 23-42.

${ }^{12}$ Melina Piglia "En torno a los Parques Nacionales: primeras experiencias de una política turística nacional centralizada en la Argentina (1934-1950)", PASOS Revista de Turismo y Patrimonio Cultural, 10.1 (2012): 61-73.
} 
Ante lo expuesto cabe preguntarse, entonces, ¿en qué momento -y en base a qué criterios- un lugar se constituye como turístico? ¿Qué rol tuvieron los parques nacionales en el desarrollo turístico del país durante la primera mitad del siglo XX? ¿Qué estrategias implementaba la Dirección Nacional de Parques para seleccionar el lugar donde llevar adelante el proceso de turistización?, ¿qué particularidades adquiere el área como lugar turístico a partir del establecimiento de un área protegida y cómo afecta a las localidades aledañas? ¿Quiénes definen las características que señalan la "atractividad" del lugar turístico? ¿Cuáles son esas características y qué implicancias tienen estos procesos en el territorio? Consideramos que los interrogantes propuestos se plantean en torno a una problemática central que gira en torno a la relación que se establece entre la creación de áreas naturales protegidas y las localidades aledañas a ellas. Así como la conformación del Parque Nacional Nahuel Huapi (1934) buscó transformar a San Carlos de Bariloche en un lugar turístico de nivel internacional; en este artículo sostenemos que hubo una intención por replicar la experiencia con la creación del Parque Nacional Lanín (1937), a partir del cual se procuró la transformación de San Martín de los Andes en un mismo sentido.

El objetivo de este trabajo es analizar el proceso de creación de un lugar turístico a partir de las intervenciones promovidas por la Dirección de Parques Nacionales que se inicia con el establecimiento de un área protegida, en este caso, el Parque Nacional Lanín. Para ello, nos interesa analizar las transformaciones territoriales ocurridas en San Martín de los Andes. El marco temporal abordado se inicia con la creación de la reserva en 1937 y finaliza en 1955 con el inicio de la provincialización de los territorios nacionales.

La metodología consistió en el análisis de bibliografía especializada y fuentes primarias de distintas procedencias. De la Administración de Parques Nacionales consultamos, principalmente, las Memorias de los años 1935, 1937, 1938-1949 y documentación del Archivo Central y del Programa Pobladores y Comunidades de la Dirección Nacional de Conservación de Áreas Protegidas. También examinamos los resultados publicados de los Censos Nacionales y de Territorios Nacionales correspondientes al período 1912-1947. Por último, se revisaron guías de turismo y otras publicaciones que circularon durante el período de análisis, tanto las elaboradas por Parques Nacionales como de otras procedencias.

El artículo se estructura en cinco partes: primero, un marco teórico del que partimos para nuestro caso de estudio; en segundo lugar, introduciremos los antecedentes y la creación del Parque Nacional Lanín para enmarcar el inicio del proceso que estudiamos; tercero, nos centrarnos en las intervenciones en el territorio, con énfasis en aquellas orientadas a la implementación de la actividad turística; en cuarto lugar, pondremos el foco en la localidad de San Martín de los Andes y en las transformaciones urbanísticas durante este periodo; por último, retomaremos las preguntas y objetivos del trabajo en las reflexiones finales. 


\section{Marco teórico}

El marco conceptual en el que se inscribe este trabajo toma como principal premisa que los destinos turísticos se configuran como resultado de procesos históricos específicos en los que intervienen diferentes actores sociales, que pueden ser locales o externos al lugar, con intereses heterogéneos $y$, por lo tanto, no exentos de conflictos entre ellos. En estos procesos, la práctica turística requiere y produce, al mismo tiempo, un espacio material, conceptual y vivido. ${ }^{13}$ Nuestra reflexión se enmarca alrededor de tres ejes principales: a nivel teórico, retomamos algunos trabajos que, desde la geografía, nos permiten comprender el vínculo entre espacio y actividad turística; consideramos relevante indagar en particular cómo el turismo se espacializa y se construye un territorio turístico. ${ }^{14}$

En este sentido, J. E. Sánchez considera que hay dos procesos que intervienen en la dinámica territorializadora del turismo. ${ }^{15}$ En primer lugar, se requiere la valorización de ciertos elementos o recursos ya sean naturales o culturales: la condición de "atractivos turísticos" otorgada a determinados atributos de los lugares no es inherente a ellos; por el contrario, se trata de "[...] una asignación social, esto es, el resultado de un proceso social que conduce a otorgarle valoración positiva que concita el interés por utilizarlo o conocerlo, transformándolo de este modo en un atractivo turístico". ${ }^{16}$ Estos procesos sobre qué seleccionar y valorizar como destinos y atractivos turísticos -que configurarán ciertas modalidades- no se producen espontáneamente, sino que existen actores -son sus intereses y posiciones de poderque orientan esas decisiones que tendrán su incidencia material y simbólica. Todo ello produce transformaciones que configuran territorios turísticos. ${ }^{17}$ En segundo lugar, para que el espacio pase a organizarse en torno a la actividad turística, se debe dar un proceso de doble funcionalización complementaria: mientras que un espacio se destina directamente al ocio, otro servirá para la estadía de la población que se ha desplazado para hacer uso del primero. ${ }^{18} \mathrm{El}$ resultado es que "el espacio de ocio pasa a ser un espacio de uso no mercantilizado, mientras que los espacios complementarios serán realmente los que asumirán el papel económico como medio de producción directo". ${ }^{19}$

\footnotetext{
${ }_{13}$ Analía Almirón, "La dimensión espacial del turismo. Hacia una comprensión del turismo desde la espacialidad como construcción social de lugares", Espacio, espacialidad y multidisciplinariedad. Marta I. Kollman (coord.) (Buenos Aires: Eudeba, 2011) 147.

${ }^{14}$ Rodolfo Bertoncello, "Turismo y territorio. Otras prácticas, otras miradas”, Aportes y transferencias, 6.2, (2002): 29-50.

${ }^{15}$ Joan-Eugeni Sánchez, Espacio, economía y sociedad (Barcelona: Siglo XXI, 1991).

${ }^{16}$ Rodolfo Bertoncello, "Presentación", Turismo y geografía. Lugares y patrimonio natural-cultural de la Argentina, Rodolfo Bertoncello (comp.) (Buenos Aires: Ciccus, 2008) 7.

${ }^{17}$ Rodolfo Bertoncello "Turismo y territorio. Otras prácticas, otras miradas", Aportes y transferencias, 6.2, (2002): 29-50.

${ }^{18}$ Eugeni Sánchez 150.

${ }^{19}$ Eugeni Sánchez 164.
} 
Un segundo eje consiste en la recuperación de las herramientas y enfoques propios de la Historia para pensar esta complejidad de procesos desde un punto de vista diacrónico. La historia sociocultural tiene mucho que decir sobre el desarrollo del turismo, "[...] poniendo atención a la problemática del uso del tiempo libre y el acceso al ocio del conjunto de la sociedad $[\ldots]]^{20}{ }^{20}$ En este caso ese aspecto es abordado solo parcialmente, mientras que los aportes de la historia regional cobrarán especial relevancia a la hora de pensar en transformaciones territoriales que se enmarcan necesariamente en lógicas de mayor alcance que las de la zona acotada que constituye nuestro caso de estudio. ${ }^{21}$ El enfoque empírico a través del análisis de las sucesivas implementaciones y modificaciones de las actividades productivas toman en cuenta esa dinámica regional, al mismo tiempo que retoma una línea de trabajo sobre historia de las ciudades turísticas. ${ }^{22}$ En síntesis, la perspectiva histórica posibilita realizar una lectura de diferentes temporalidades y ritmos en los cambios que se dieron en la economía y la sociedad en este lugar particular, con marcadas diferencias respecto de la historia nacional.

Como tercer eje, recuperamos los antecedentes a nivel nacional e internacional en torno al problema de los parques nacionales y su vínculo con la introducción de actividades turísticas. Esta relación estuvo presente desde el inicio de esta experiencia en Norteamérica, donde los parques se pensaron como espacios públicos para uso recreativo, particularmente como lugares a visitar. ${ }^{23}$ La creación de sucesivas áreas protegidas en ese y otros países fue adoptando, de diferentes maneras, algún tipo de desarrollo turístico. Vale aclarar que, desde la implantación del "modelo" de Yellowstone, la creación de este tipo de áreas protegidas se asoció a una valorización de la belleza escénica de lugares pensados como "vírgenes". Como afirma Mallarach, en tanto imagen idealizada del Edén, "[...] se exigía que no tuviera pobladores", ${ }^{24}$ a pesar de que, con frecuencia, esta afirmación no se ajustara la situación real. Entonces, la imposición de la actividad turística en lugares poco urbanizados, no colonizados o que, hasta el momento, tenían escasos vínculos con centros económicos consolidados, trae aparejadas dos consecuencias importantes. Por un lado, la necesaria reorganización territorial en torno a ella que lleva a algunos autores a hablar de un funcionamiento de enclave $^{25}$ e incluso a pensar a los parques nacionales desde una perspectiva política

\footnotetext{
${ }^{20}$ Elisa Pastoriza La conquista de las vacaciones. Breve historia del turismo en Argentina (Buenos Aires: Edhasa, 2011) 18.

${ }^{21}$ En este sentido, las investigaciones realizadas por Susana Bandieri son un punto de partida inevitable para conceptualizar la Patagonia y, particularmente, las áreas de las cordilleranas.

${ }^{22}$ En Argentina, algunos ejemplos son el trabajo de Elisa Pastoriza sobre la historia de la ciudad de Mar del Plata y, en la región patagónica -especialmente significativo para nuestro caso-, el estudio de Laura Méndez sobre la historia de Bariloche (Méndez, Laura Estado, frontera y turismo. Historia de San Carlos de Bariloche. Buenos Aires: Prometeo, 2010).

${ }^{23}$ Warwick Frost y Colin M. Hall (eds.), Tourism and National Parks: international perspectives on development, histories and change (London: Routledge, 2009).

${ }^{24}$ Josep Mallarach, "Parques Nacionales versus Reservas Indígenas en los Estados Unidos de América: un modelo en cuestión”, Ecología Política, 10 (1996): 26.

${ }^{25}$ Carlos Andrés Durán, “Gobernanza en los Parques Nacionales Naturales colombianos: reflexiones a partir del caso de la comunidad Orika y su participación en la conservación del Parque Nacional Natural Corales del Rosario y San Bernardo" Revista de Estudios Sociales 32 (2009): 60-73.
} 
como pequeños Estados. ${ }^{26}$ Por el otro, la relación que se establece desde el inicio con la población pre-existente resulta contradictoria o conflictiva, lo cual explica la continuidad hasta la actualidad tensiones y disputas territoriales que se dan alrededor del binomio conservación/explotación de la naturaleza como recurso.

Por último, cabe destacar los aportes de la historiografía regional patagónica, cuyo estudio del vínculo entre Parques Nacionales, territorio y turismo ha sido ampliamente abordado, principalmente en el caso de la relación entre el Parque Nacional Nahuel Huapi y la ciudad de San Carlos de Bariloche. La noción de frontera ocupa un lugar preponderante en estos análisis y explica el interés especial otorgado desde el Estado nacional al objetivo de desplegar una serie de políticas dirigidas al ordenamiento territorial en la región norpatagónica andina. ${ }^{27}$ Un referente en este sentido es Pedro Navarro Floria, quien ha estudiado cómo se han ido desplegando diferentes representaciones y transformaciones en el territorio norpatagónico a lo largo del siglo XX. La creación del parque nacional se enmarca, desde esta perspectiva, en un proceso histórico caracterizado por una serie de cambios y resignificaciones en torno a la problemática de desarrollo local y regional en la zona. ${ }^{28}$ Esto implica considerar, asimismo, que las políticas públicas centradas en los parques y la visión sobre conservación y turismo que subyacen a ellas fueron cambiando a lo largo del tiempo. $^{29}$

Desde este enfoque, consideramos relevante indagar sobre el rol -o incidenciaque la construcción de las áreas protegidas y, en particular, los parques nacionales, han tenido en estos procesos de espacialización del turismo y la conformación de territorios turísticos.

\section{Las áreas protegidas como impulsoras de procesos turísticos}

En Estados Unidos ya había habido experiencias previas de manejo estatal de tierras con usos recreativos, como la Reserva de Hot Springs en Arkansas (1832) o la concesión en 1864 de Yosemite Valley (California) como espacio para uso público

\footnotetext{
${ }^{26}$ Lary M. Disalver and William Wyckoff, “The Political Geography of National Parks" Pacific Historical Review, 74. 2, (2005): 237-266.

${ }^{27}$ Laura Méndez,Estado, frontera y turismo. Historia de San Carlos de Bariloche (Buenos Aires: Prometeo, 2010).

Paula G. Núñez y otros. "Patagonia, de margen exótico a periferia turística. una mirada sobre un área natural protegida de frontera". PASOS - Revista de Turismo y Patrimonio, 10.1 (2012): 47-59.

${ }^{28}$ María de los Ángeles Picone, La problemática del cambio en los proyectos de desarrollo para $S$. C. de Bariloche (1930-1943) [en línea]. Tesis de Licenciatura, Universidad Católica Argentina, Facultad de Ciencias Sociales, Políticas y de la Comunicación. Departamento de Historia, 2011. Disponible en: http:// bibliotecadigital.uca.edu.ar/repositorio/tesis/problematica-cambio-proyectos-desarrollo-bariloche.pdf

${ }^{29}$ Vejsbjerg, Laila, “Turismo, conservación y políticas públicas en espacios de frontera. El rol de los parques nacionales en la Norpatagonia andina argentina (1916-1976)" (VII Simposio Internacional y XII Jornadas Nacionales de Investigación - Acción en Turismo CONDET. Facultd de Turismo, UNCo, Neuquén, octubre 2015).
} 
y recreativo. ${ }^{30}$ Según Frost y Hall, el potencial para desarrollar actividades centradas en el turismo fue un factor relevante para la creación del primer parque nacional, Yellowstone. ${ }^{31}$ Más allá del fundamento conceptual e ideológico que señalamos anteriormente, estos autores advierten que, en el marco de las expediciones que dieron origen a la voluntad por crear dicha área protegida, sus participantes vaticinaban las posibilidades económicas del lugar. La pregunta que se hacían aquellos hombres de negocios giraba en torno a qué elementos de ese entorno podrían motivar a los hipotéticos visitantes a pagar una entrada por verlos. De hecho, como afirma Nash, la ley que declaraba la creación de este parque en 1872 no hablaba aún de una protección de la naturaleza en términos abstractos, sino que se centraba en las "curiosidades" y "maravillas" allí presentes. ${ }^{32}$

Entre 1890 y 1910 se crearon otros diez parques, la mayoría de ellos en zonas montañosas de características al primero y ubicados, principalmente, en el oeste del país. La monumentalidad de ciertos elementos naturales como volcanes, glaciares y árboles milenarios protagonizaban estos paisajes destinados a maravillar a los visitantes. ${ }^{33} \mathrm{El}$ interés por la actividad era compartido no solo por funcionarios y hombres de negocios locales, sino también por las grandes compañías de ferrocarriles, llamadas a ser socias fundamentales para posibilitar la conexión turística de estas zonas. Se constituyeron en importantes partícipes de la emergente actividad turística en torno a estos espacios, no solo a través de la provisión del transporte, sino también el alojamiento mediante la construcción de grandes hoteles en zonas alejadas de las ciudades y un rol relevante en cuanto a la promoción y la configuración de una cierta imaginería alrededor de los parques. ${ }^{34}$

Como adelantamos en la introducción, este modelo de parques fue rápidamente replicado en otros lugares, en principio en países de similares características considerados como sociedades “de frontera"- como Australia (1879), Canadá (1887) y Nueva Zelanda (1887). En ellos, la idea de desarrollo económico regional a través de su valorización como atractivos turísticos estaba, como en Estados Unidos, dentro de los objetivos que se buscaba alcanzar. ${ }^{35}$

En Argentina, como señala Fortunato, apareció tempranamente la voluntad de crear áreas naturales protegidas con la experiencia norteamericana en la mira. ${ }^{36}$ Este primer impulso, como en el país del norte, estuvo enmarcado en un proceso más amplio de consolidación del dominio territorial. ${ }^{37}$ Durante este primer momento, la

\footnotetext{
${ }^{30}$ Vejsbjerg, Laila 24.

${ }^{31}$ Warwick Frost y Colin M. Hall .17.

${ }^{32}$ Roderick Nash 730.

${ }^{33}$ Warwick Frost y Colin M. Hall 18.

${ }^{34}$ Peter Blodgett, "Defining uncle Sam's playgrounds: Railroad advertising and the National Parks, $1917-$ 1941” Historical Geography, 35 (2007): 113.

${ }^{35}$ Peter Blodgett 110.

${ }^{36}$ Norberto Fortunato 730.

${ }^{37}$ Eugenia Scarzanella, "Las bellezas naturales y la nación: los parques nacionales en Argentina en la
} 
"belleza natural" conformaba un atributo en el que el nacionalismo de principios de siglo encontró "la encarnación simbólica de la patria para ofrecerla al culto cívico". 38 El primer proyecto de parque nacional nació con la donación de tres leguas cuadradas de superficie en la zona del lago Nahuel Huapi realizada por Francisco P. Moreno en 1904. Esta porción era una parte de las tierras que el Estado le había cedido por su papel como perito en la delimitación de la frontera con Chile. Moreno las cedió con el objetivo de preservar la zona a través de la creación de un parque nacional, constituyéndose en el primer proyecto de este tipo en el país, que llevó a la creación del Parque Nacional del Sud en 1922. Sin embargo, la institucionalización de las áreas protegidas se terminó consolidando algunos años más tarde, con la creación de la Dirección de Parques Nacionales (DPN) bajo el liderazgo de Ezequiel Bustillo, quien ocupó el rol de director entre 1934 y $1943 .{ }^{39}$

El clivaje de los años 30 marcó un cambio en la perspectiva del Estado sobre el territorio nacional en general y sobre la preocupación por las fronteras en particular. ${ }^{40}$ Si bien es cierto que las políticas y los proyectos de intervención territorial en la región no fueron una novedad de este período, el contexto de entreguerras le imprimió una connotación específica y modificó algunas de sus orientaciones. Durante este período la Patagonia era el centro de preocupaciones geopolíticas que movilizaban debates en la opinión pública, resultando en la construcción de un discurso nacionalista en torno a la región. ${ }^{41}$ En el marco de un discurso propio de la época, el refuerzo de ideas nacionalistas se volcaba a fundamentar la voluntad por intervenir zonas "alejadas"

primera mitad del siglo XX", Revista Europea de Estudios Latinoamericanos y del Caribe, 73 (2002): 5-21

${ }^{38}$ Eugenia Scarzanella 6.

${ }^{39}$ Como señala Navarro Floria, antes de la intervención de la DPN bajo la gestión de Bustillo, se pueden identificar una serie de antecedentes importantes en cuanto a la definición de un lugar turístico en la zona cordillerana de la Norpatagonia. La rehistorización desde una perspectiva local de las primeras décadas del siglo XX permite encontrar, tanto en un proceso de resignificación del espacio y su sistematización en el proyecto Bailey Willis, sumado a la participación de actores locales, un contenido material e inmaterial relevante como factores en el proceso territorializador de la región. (Pedro Navarro Floria, "La "Suiza argentina", de utopía agraria a postal turística: la resignificación de un espacio entre los siglos XIX y XX" (3eras Jornadas de Historia de la Patagonia. San Carlos de Bariloche, noviembre 2008).

${ }^{40}$ El nuevo contexto económico y político de la década de los treinta trajo aparejado un proceso de transformación en la organización del territorio nacional, tanto desde el punto de vista material como en cuanto a las representaciones que se hacían de él. Como señalan Ballent y Gorelik, el agotamiento de la economía agroexportadora trajo consigo una "nueva actitud pública favorable a la diversificación productiva". (Anahí Ballent y Adrián Gorelik. "País urbano o país rural: la modernización territorial y su crisis". En Cattaruzza, Alejandro (dir.) Nueva Historia Argentina. Buenos Aires: Sudamericana, 2001) 145-200. Este periodo se caracterizó por la introducción de una renovada preocupación por las economías regionales, con vistas a la creación de un mercado nacional que se saliera del esquema planteado por ese "desarrollo hacia afuera" característico de fines del siglo XIX. La Patagonia fue una de las regiones sobre las que se posó esta mirada estatal: “(...) la Patagonia ha vivido librada a sus propias fuerzas y recursos y todavía no se ha aplicado un plan eficaz de colonización de sus tierras más fértiles, ni se ha desarrollado una política moderna de fomento de sus grandes posibilidades económicas que tan fecunda en bienes habría sido para la Nación". (José María Sarobe, La Patagonia y sus problemas. (Buenos Aires, Editorial Centro de Estudios Unión para la Nueva Mayoría, 1999) 45.

${ }^{41}$ Carlos Masotta, "Un Desierto para la Nación. La Patagonia en las Narraciones del Estado de la Concordancia (1932-1943)", (IV Congreso Chileno de Antropología. Colegio de Antropólogos de Chile A. G, Santiago de Chile, 2001). 
como parte de un objetivo de consolidar las fronteras nacionales. La intervención estatal en el desarrollo local no era nueva; sin embargo, a partir de la creación de una dependencia específica en el Estado nacional, se puso en marcha la intervención territorial motivada fuertemente por la imposición de una planificación turística centralizada. ${ }^{42}$ Mediante el otorgamiento de una nueva base económica se buscaba vincular este desarrollo con el mercado nacional y con el centro del país, en detrimento de una dinámica económica-social con orientación trasandina.

Las principales líneas seguidas por la DPN en materia turística se pueden ver materializadas en su principal obra: la transformación de San Carlos de Bariloche en uno de los destinos turísticos más importantes del país. Para ello, se trabajó desde diferentes aspectos, que podemos resumir en cuatro grandes líneas: primero, la conceptualización de un paisaje "natural" ${ }^{43}$ y su promoción; segundo, el control de actividades productivas y formas de ocupación del espacio en las áreas rurales. Tercero, la construcción de obras de infraestructura: para el acceso al lugar, para proveer servicios de uso colectivo y específicamente turística (hotelera). Por último -y vinculado al punto anterior-, la planificación urbana y la regulación de la construcción fue un punto importante dentro de las políticas de la DPN.

La promoción de la zona se realizó, principalmente, mediante la impresión de folletos, afiches y guías, además de la utilización de fotografías y material fílmico elaborado especialmente para proyectarse en espacios públicos. Además, una parte importante de la promoción se canalizaba mediante la prensa, con notas impresas en medios de alcance nacional. El uso de imágenes era particularmente importante y se insertaba en un marco en el que el turismo como práctica social y actividad económica estaba instalado en la opinión pública desde la década anterior.

Un aspecto que nos interesa resaltar es el público para el que se pensaba esta promoción, al menos en sus años iniciales. La zona del Nahuel Huapi se construía discursiva y pictóricamente como lugar turístico de ciertas características paisajísticas, ya fuera por su naturaleza de montaña y lacustre, así como las experiencias que se prometían. La pesca y la caza encontraban allí condiciones ideales -lo cual no resultaba casual, teniendo en cuenta que se habían introducido diversas especies animales exclusivamente para ello. La nieve fue otro elemento que la DPN se encargó de configurar como parte de ese lugar turístico, para lo cual trabajó en el fomento de los deportes invernales, principalmente el esquí. Presentadas como experiencias a través de las cuales se consumaba el disfrute de los parques, todas ellas eran actividades con las cuales estaba familiarizada la clase alta argentina por sus frecuentes viajes a Europa, al menos antes de que la Primera Guerra Mundial y el período de entreguerras los limitaran. Entonces, se presentaba a los parques como lugares que podían ofrecer las mismas vivencias que otros destinos del viejo continente. Se pretendía asimismo

\footnotetext{
${ }^{42}$ Melina Piglia 35.

${ }^{43}$ Esta conceptualización implicó una construcción simbólica, pero también material, de lo que debía ser esa "naturaleza". Dicho diseño incluía la introducción de especies exóticas en la región, con las respectivas consecuencias para la flora y fauna locales. Se introdujeron ciervos y jabalíes para fomentar la caza mayor, truchas para la pesca deportiva y pinos para la reforestación.
} 
cumplir con las expectativas de un público exigente, en tanto se planeaba hacer de Bariloche un destino internacional. La construcción del exclusivo Hotel Llao Llao con campo de golf es muestra de esta intención.

Por otra parte, las instalaciones turísticas no servían de nada si la ciudad no era tomada en cuenta en su conjunto para adecuarla a la nueva función, lo cual implicaba pensar en su capacidad de garantizar servicios básicos a su población permanente, a los visitantes y, además, mantener una cierta estética. La DPN invirtió gran parte de sus recursos en la modificación de Bariloche, que era proyectada, según Bustillo, como:

[...] una gran ciudad central de frontera y con el magnetismo necesario para atraer desde el interior del país, la corriente demográfica que nos neutralizara de Chile que empezaba y a ahogar o diluir el débil sentimiento nacional [...]. Prolongación de esa idea [...] era fundar una serie de pueblos o villas, que a manera de satélites, contribuyeran a consolidar la jurisdicción argentina y de paso a constituir una profunda penetración que llegase lo más cerca posible de la línea divisoria con nuestro vecino. ${ }^{44}$

El rol de las ciudades como hitos de avanzada civilizatoria sobre el territorio formó parte del discurso de Bustillo desde el inicio de su gestión. En ellas se concentraría la actividad turística, llamada a ser el motor del florecimiento económico de la región y base sobre la cual se fortalecería entonces la tan deseada consolidación de la soberanía en la cordillera. En sus memorias, Bustillo relata cómo, en una conversación con el expresidente Justo, este le expresaba que "[...] las ciudades eran organismos vivos que no se hacían por decreto". ${ }^{45}$ A lo cual él había respondido con ejemplos internacionales, pero también destacando su propia labor emprendida en el sur del país, donde esta función era vista como fundamental. Esta intervención centralizada, por otra parte, no se veía exenta de tensiones, teniendo en cuenta que no coincidía necesariamente con algunos intereses locales o regionales. De hecho, aunque la ley de Parques Nacionales ( $\left.n^{\circ} 12.103 / 1934\right)$ explicitaba que los municipios al interior de las reservas conservaban su autonomía; Bustillo intentó, sin éxito, eliminar esta disposición.

\subsection{La creación del Parque Nacional Lanín (1937)}

El Parque Nacional Lanín (PNL) fue creado en 1937 como resultado de un estudio previo, realizado en 1936 por cuatro comisiones exploradoras enviadas con el objetivo de determinar la ubicación y conveniencia para la creación de nuevos parques en los Territorios Nacionales de Neuquén, Chubut y Santa Cruz. Se localiza en la zona cordillerana de la provincia de Neuquén (Fig. 1). En el sector sur del parque nacional se encuentra la localidad de San Martín de los Andes, sede de su Intendencia. En 1897

\footnotetext{
${ }^{44}$ Ezequiel Bustillo, El Despertar de Bariloche. Una estrategia patagónica (Buenos Aires: Editorial y Librería Goncourt, 1968) 281.

${ }^{45}$ Ezequiel Bustillo 197.
} 
se había conformado allí la Colonia Pastoril Maipú. Desde el centro hasta su extremo sur, el Parque posee un total de 412.000 hectáreas. Limita en el sur con el Parque Nacional Nahuel Huapi -que contiene las ciudades de Bariloche. Villa La Angostura y Villa Traful-, en el norte finaliza en el lago Ñorquinco; en el este, sigue una línea más irregular a la altura de San Martín de los Andes y, por último, en el oeste, el límite es la frontera con Chile. Debido a esta ubicación y a su gran extensión, muchos de los pasos fronterizos del sur neuquino quedaran incluidos dentro de su superficie.
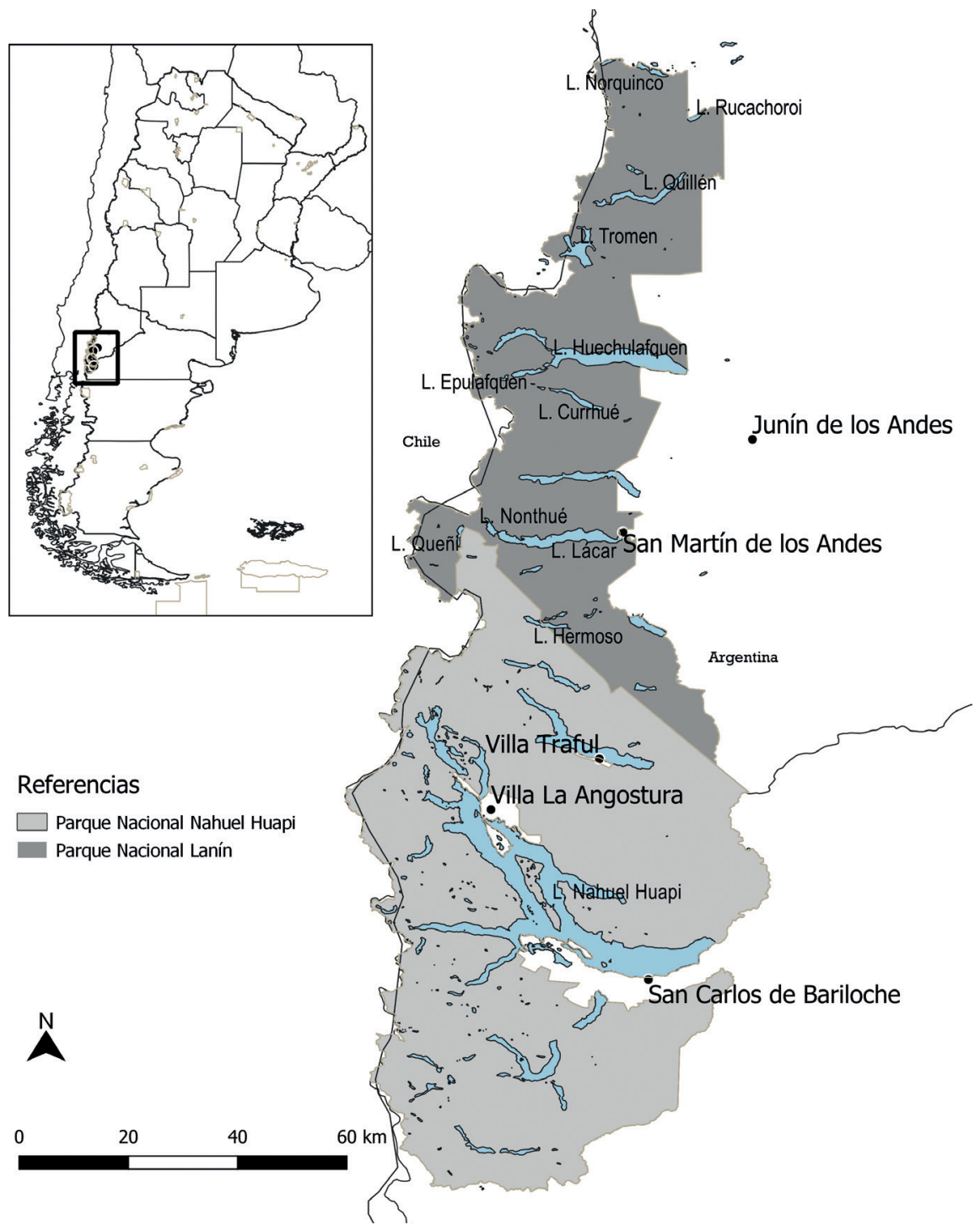

Figura 1. Localización de Parques Nacionales Lanín y Nahuel Huapi.

Fuente: elaboración propia. 
Luego de concretada la llamada "Conquista del Desierto" a fines del siglo XIX, los primeros asentamientos de la región se organizaron alrededor de fuertes y fortines a lo largo de la cordillera, a lo que se sumó la creación de Colonias agrícola-ganaderas en las que habitaban, en principio, población indígena preexistente, soldados devenidos productores y sus familias, al mismo tiempo que se iban incorporando migrantes internos y extranjeros. ${ }^{46}$ En el caso de la zona en la que hoy se encuentra San Martín de los Andes, se creó la Colonia Maipú (1897) en el área del fuerte del mismo nombre. Un año después, se fundó el pueblo en su extremo Este, a orillas del lago Lácar. ${ }^{47} \mathrm{Su}$ creación estuvo motivada por la persistencia de disputas limítrofes con Chile en esa área, teniendo en cuenta que dicho conflicto se resolvería oficialmente cuatro años después, con el laudo arbitral británico de $1902 .{ }^{48}$ El Regimiento $3^{\circ}$ de Caballería se instaló en el valle ocupado hasta ese momento por indígenas, desplazados a partir de entonces hacia las afueras del nuevo pueblo. ${ }^{49}$ Los militares estuvieron a cargo de la distribución de las tierras y el trazado del nuevo centro urbano, así como de la autoridad local hasta 1911, año en el que se creó la primera Comisión de Fomento.

La economía neuquina durante este período se centraba en la explotación primaria, principalmente ganadera, actividad que se practicaba antes de la colonización del espacio por el Estado. Las tierras del sur cordillerano se habían privatizado más rápidamente por tener mejores condiciones productivas; allí se concentraban los actores más beneficiados por esta actividad: los grandes estancieros que contaban con mayor capacidad de llevar adelante una producción "eficiente" gracias al aporte de inversiones en capital, y al hecho de que controlaban el circuito de comercialización

\footnotetext{
${ }^{46}$ Susana Bandieri, Historia de la Patagonia (Buenos Aires: Sudamericana, 2005).

${ }^{47}$ Estudios arqueológicos demuestran no solo su poblamiento de larga data, sino también unas características compartidas a ambos lados de la cordillera. En este sentido, Alberto Pérez y otros ponen en cuestión la tradicional distinción entre pueblos indígenas cazadores-recolectores hacia el lado oriental de la cordillera y productores de alimentos en su vertiente occidental. Esta conceptualización orientada a la creación de una imagen de una sociedad con una economía meramente extractiva forma parte de una construcción discursiva, elaborada en función de intereses dominantes en el momento, y que operó como justificación de la violencia ejercida por el Estado sobre esa población. Pérez, Reyes Álvarez y Erra. "Economías mixtas de la Patagonia Nororiental Argentina y Centro y Sur de Chile" en Nicolletti, María Andrea y Núñez, Paula (Comp.) Araucanía - Norpatagonia: la territorialidad en debate: perspectivas ambientales, culturales, sociales, políticas y económicas. (Instituto de Investigaciones en Diversidad Cultural y Procesos de Cambio-CONICET-UNRN, Bariloche, 2013) 132.

${ }^{48}$ Como observa F. Félix de Amador en su ensayo de historia local, el pueblo fue fundado por el Ejército a orillas de un lago que, al desaguar en el Pacífico, estaba en el centro de los debates sobre el criterio de "divisoria de aguas" para la delimitación política entre Argentina y Chile. (F. Félix de Amador Reseña histórica de San Martín de los Andes (San Martín de los Andes: Didot, 1998 [1948]) 4.

${ }^{49}$ Santiago Polito Belmonte, "Con el arribo del hombre blanco, 'las leyes se acatan, pero no se cumple'", Comisión del Centenario y Fundación San Martín de los Andes, El libro del centenario de San Martín de los Andes (San Martín de los Andes: Publisher S.A., 1999) 75.
} 
para la colocación de sus productos. ${ }^{50}$ Como señalan Blanco ${ }^{51}$ y Méndez y Sougarret, ${ }^{52}$ la desconexión de esta zona con la economía atlántica las hacía poco atractivas para las inversiones nacionales, motivo por el cual muchas de ellas fueron compradas rápidamente por capitales trasandinos por su vínculo con aquel mercado.

En la Colonia Maipú, una primera distribución de las tierras productivas había beneficiado a un reducido grupo de propietarios y arrendatarios, dedicados en su mayoría a la cría ovina y bovina, lo cual se constata al observar el predominio de grandes unidades productivas en los censos. ${ }^{53}$ En la zona se desarrollaban también otras actividades primarias para el consumo, como la agricultura y la explotación y procesamiento de maderas de los bosques. Esta última actividad forestal, aunque en conjunto, empleaba una cantidad considerable de trabajadores y tenía como objetivo el mercado local. La ganadería era la única actividad económica que se insertaba en un circuito mercantil más amplio, en tanto su demanda superaba el autoabastecimiento de los pobladores locales y vinculaba a la economía de la zona del Lácar con otros centros de consumo, aunque con destino transandino. El predominio de esta actividad era acompañado por el establecimiento de población dispersa en el territorio. ${ }^{54}$

Una vez creado el Parque Nacional Lanín, la Colonia Maipú y el pueblo quedaron bajo jurisdicción de la DPN, a cargo de la reglamentación para el ordenamiento territorial. La ley 12.103 de 1934 -que creaba los parques Nahuel Huapi e Iguazú- había dejado asentados los principios fundamentales para ello, al indicar que las tierras fiscales dentro de sus límites -declaradas bienes de dominio público- quedaban bajo un control que se definía de manera amplia, incluyendo la posibilidad de: "Disponer la ubicación y trazado de centros de población y lotes agrícolas o pastoriles dentro de los parques [...], fijar precios y condiciones para su enajenación, concederlos en venta y recabar del Poder Ejecutivo el otorgamiento de títulos definitivos a los compradores" (Art. No16, inciso n). Sin embargo, vale aclarar que la jurisdicción de la DPN exceptuaba el derecho de los municipios y de los propietarios particulares situados en su interior, aspecto sobre el que volveremos más adelante.

\footnotetext{
${ }^{50}$ Susana Bandieri, “Actividades económicas y modalidades de asentamiento", Susana Bandieri, Orietta Favaro y Marta Morinelli (eds.) Historia de Neuquén (Buenos Aires: Plus Ultra, 1993) 147-261.

${ }^{51}$ Graciela Blanco.

${ }^{52}$ Laura Méndez y Jorge Muñoz Sougarret 132.

${ }^{53}$ En el Censo Nacional de 1914, un 30\% de las explotaciones agropecuarias del Departamento Los Lagos tenían una extensión superior a las 1.000 hectáreas y representaban, en conjunto, un $90 \%$ del total de la superficie ocupada por estas explotaciones.

${ }^{54} \mathrm{El}$ análisis de los censos permite constatar el crecimiento del pueblo como centro de servicios para el área rural circundante en la que se desarrollaban estas actividades primarias. Un rasgo específico de la zona era el peso de población extranjera y, dentro de este grupo, la fuerte presencia trasandina. El amplio predominio de la población censada como "chilena" se encuentra vinculada tanto a las características de asentamiento y movilidad de la población pre-existente, como a la continuidad en las relaciones económicas establecidas entre la zona y las ciudades del sur chileno.
} 
Aunque con algunas modificaciones a largo de los años, las intervenciones territoriales en el PNL estuvieron orientadas, según lo señalado hasta aquí, a lograr una organización "racional" del espacio. El objetivo era regular el tipo de actividades que podrían realizarse en cada una de las áreas bajo las que se clasificaron las más de 400 mil hectáreas del área protegida. En general, esta zonificación otorgaba prioridad a la conservación de ciertas características del entorno natural, al que se pretendía mantener "inalterado".

En agosto de 1947 se presentó un proyecto para formalizar este ordenamiento en el parque, cuyo fin era consolidar una "clasificación racional de su superficie y definición orientadora del destino a darse" ${ }^{55}$. Se establecía la división en áreas intangibles, recreativas y de explotación conservativa (Tabla 1). El hecho de que la zona intangible representara menos de un tercio de la totalidad de la superficie del parque nos permite verificar lo señalado hasta aquí en cuanto a la necesidad de matizar una idea de estas áreas protegidas como lugares pensados únicamente para la conservación de la naturaleza en su condición intacta. Por otra parte, en cuanto a la definición de las áreas de "explotación conservativa", cabe destacar que, en el mismo expediente, se estableció que las características poco propicias del suelo del Parque Nacional Lanín lo hacían no apto para la actividad pastoril. Por esta razón se dispuso el control del ingreso de hacienda al parque y se decidió el traslado de algunos pobladores dedicados a esta actividad; mientras que se daba a toda la extensión de esta área el destino exclusivo de explotación forestal.

Tabla 1. Zonificación del Parque Nacional Lanín según uso del suelo (1947/1953)

\begin{tabular}{cccc}
\hline \multirow{2}{*}{ Áreas } & \multicolumn{2}{c}{ Superficie en hectáreas } & Variación \\
\cline { 2 - 3 } & $\mathbf{1 9 4 7}$ & $\mathbf{1 9 5 3}$ & porcentual \\
\hline Intangibles & 83.000 & 63.800 & $-23 \%$ \\
Recreativas & 100.000 & 151.109 & $+51,1 \%$ \\
$\begin{array}{l}\text { Explotación } \\
\text { conservativa }\end{array}$ & 108.000 & 141.770 & $+31,3 \%$ \\
\hline
\end{tabular}

Fuente: elaboración propia con base en APN/PNL/Expte. No 7913 (1947).

En 1953 se modificó la subdivisión con el objetivo de "actualizarlas". La nueva clasificación determinaba la disminución de la superficie reservada a las áreas intangibles, que pasaban de 83.000 a 63.800 hectáreas, mientras que las de explotación conservativa aumentaban de 108.000 a 141.770 y las de uso recreativo, de 100.000 a 151.109 (Fig. 2). La disminución en cuanto a la superficie intangible se debió al cambio en la clasificación de dos zonas. Una porción del área del lago Currhué (fig.1) pasó a ser recreativa, decisión fundamentada en el hecho de que la zona era visitada tanto por turistas como por población de Junín de los Andes. La segunda era una parte del área del lago Queñi (fig.1) que mantuvo su carácter de intangible solo en su porción sur -denominada a partir de entonces "área intangible Lago Hermoso"-,

${ }_{55}$ Administración de Parques Nacionales (APN), Archivo Central. Expediente No7913/1947. 
mientras que la parte restante -circundante al lago- fue declarada área de explotación conservativa. Las razones aducidas para dicha modificación se resumían en el hecho de que los bosques de esta zona se encontraban ya afectados tanto por incendios como por su explotación, a lo cual se sumaba el uso de las tierras para pastoreo de animales.

\section{Las transformaciones territoriales en los procesos de espacialización turística}

Al fomentar la actividad turística en un territorio, no solo se lo valoriza y se le atribuye un uso determinado, sino que se requiere introducir modificaciones específicas para su aprovechamiento. Según Sánchez, la particularidad de la territorialización producida por el turismo es que “[...] se aprovechan simultáneamente sus características como medio y como recurso - que lo hacen medio de producción-, al tiempo que se requiere su funcionalización a través de la producción de espacios e instalaciones complementarias para que el turista pueda usar in situ dicho espacio físico". ${ }^{56}$

En este apartado nos referiremos, en primer lugar, a las intervenciones tendientes a la conservación de lo que este autor denomina "espacio de ocio no mercantilizado" que, en este caso, estaba constituido por el parque nacional, constituido por los entornos de bosques y lagos presentados como "bellezas naturales". Este espacio, bajo estricto control, debía permanecer inmutable, al menos en algunos de sus aspectos físicos. Un segundo campo de acción es aquel orientado a la generación de infraestructura necesaria para que los turistas pudieran hacer uso de él, no solo en el área protegida, sino también en San Martín de los Andes, su puerta de entrada. Dos cuestiones son centrales en este sentido: primero, la necesidad de construir caminos hacia y dentro del parque para garantizar el acceso a la zona y la circulación por los diferentes atractivos; segundo, la oferta de alojamiento, excursiones y otros servicios propios de la actividad turística.

\subsection{La valorización social del lugar: construcción del parque nacional como atractivo turístico}

Un primer aspecto del proceso de refuncionalización del espacio a partir de la introducción de la actividad turística consiste en la valorización de un lugar cuyo principal objetivo será constituirse y conservarse como espacio para el ocio, medio de producción dentro de esta actividad. La creación del PNL fue fundamental en este sentido, porque constituía un acto de adjudicación de un valor determinado para esta porción de territorio, al mismo tiempo que aseguraba la conservación de sus características especiales, incluyendo aquellas que se imprimían deliberadamente sobre el territorio mediante una intervención que colaboraba en la construcción de una "naturaleza" diseñada. ${ }^{57}$ A ello se sumaba la promoción turística que daba a conocer

\footnotetext{
${ }^{56}$ Joan-Eugeni Sánchez 161.

${ }^{57}$ El propio Bustillo se encargaba de aclarar, cada vez que era posible, que las políticas seguidas por la DPN bajo su dirección no se orientaban con un fin de conservacionismo "ortodoxo", perspectiva en la
} 
el lugar y colaboraba en el proceso de afianzamiento de esa valorización del principal recurso, es decir, un paisaje que se presentaba como "natural" devenido atractivo turístico.

Desde su creación, una de las funciones de la DPN era generar diferentes tipos de piezas comunicacionales, ya fueran guías, fotografías, películas, para la promoción de las áreas protegidas. Su labor se complementaba con material que editaban otros actores, como guías o publicaciones en las revistas ilustradas de la época. El uso de imágenes en la promoción turística era muy importante, porque constituían una parte central del fundamento estético a partir del cual se concebía, en este caso, una "belleza natural" escenificada en esos lugares y no en otros. Como sostiene Zusman, el paisaje así considerado implica, en el contexto de su promoción turística, una acción visual específica, "contemplativa", que desencadena determinadas "sensaciones asociadas" en el espectador". ${ }^{58}$ Las imágenes funcionan como dispositivos que crean expectativas sobre lo que el visitante podrá ver, efectivamente, en la práctica turística in situ. ${ }^{59}$ Incluso desde lo discursivo, la construcción de una escenografía promovida como espacio para el disfrute se centraba en lo visual. Citamos como ejemplo un fragmento tomado de la guía "El Lanín. Parque Nacional” de Alberto De Agostini (1941), en la que el autor realiza una detallada descripción del pueblo de San Martín de los Andes:

Alrededor de la población, que se extiende en forma de un tablero de ajedrez en el llano del valle, se distinguen por entre las manchas verde oscuras de los cipreses, de los radales y de los manzanos silvestres, y las más claras de los prados y sembrados, las blancas casas de San Martín [de los Andes] rodeadas por huertas, jardines e hileras de álamos, mientras en el extremo sud la cinta azulada del lago Lácar cierra el cuadro polícromo de esta bellísima cuenca. ${ }^{60}$

Es interesante el modo en el que se construye pictóricamente la mirada sobre el pueblo que, contemplado desde algún mirador, queda enmarcado por los colores y texturas de la vegetación y los cerros, todo lo cual contextualiza y vuelve a reinsertar al centro urbano en una escena "natural" de los bosques patagónicos. La forma de fotografiar al pueblo en la figura 3, aunque no corresponde a la misma fuente resulta ilustrativa de esta forma de presentar esta mirada.

\footnotetext{
que englobaba principalmente a intereses de naturalistas o científicos para quienes los parques serían solo "santuarios" o "verdaderas universidades al aire libre, donde se vive en contacto con la naturaleza, se la siente, se la admira y se la respeta" (Bustillo 363). En cambio, él definía su postura como "ecléctica", en el que “(...) la compuerta de protección de la naturaleza auténtica (...), se abrirá o cerrará, en más o menos, según las circunstancias de ubicación y demás características de cada parque” Bustillo 370.

${ }^{58}$ Perla Zusman, "El paisaje: la razón y la emoción al servicio de la práctica turística", Rodolfo Bertoncello (comp.) Turismo y Geografia. Lugares y patrimonio natural-cultural de la Argentina. (Buenos Aires: CICCUS, 2008).

${ }^{59}$ Perla Zusman.

${ }^{60}$ Alberto De Agostini, El Lanín. Parque Nacional (Buenos Aires: S.E., 1941) 6.
} 


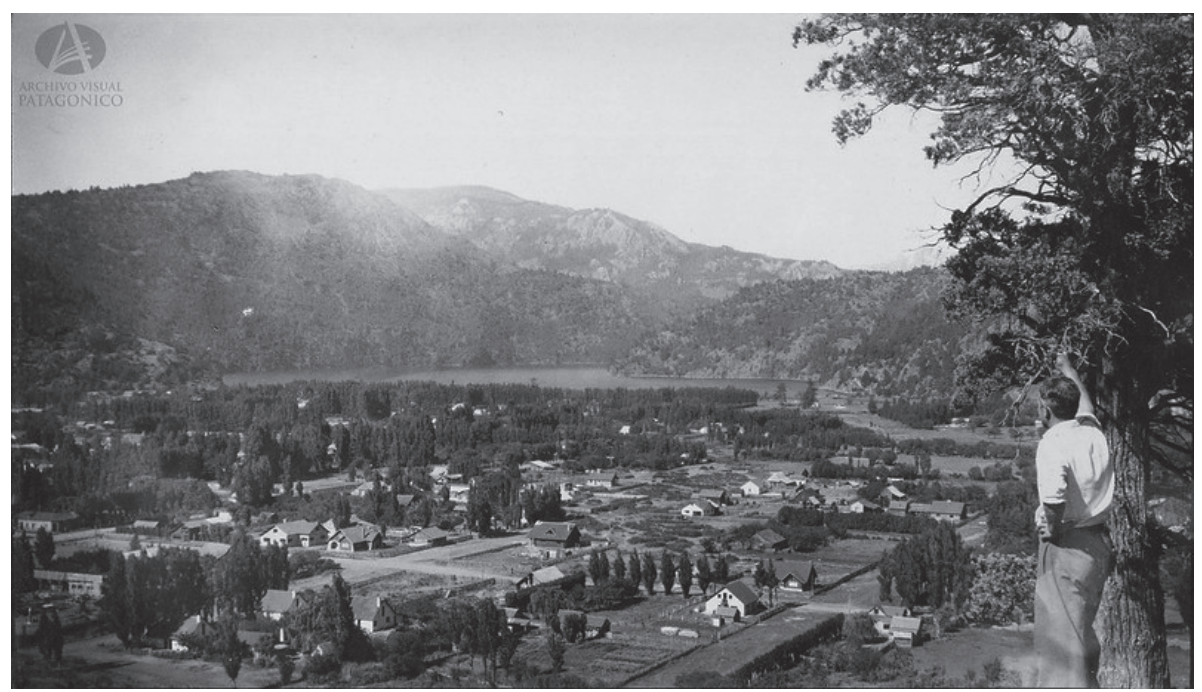

Figura 3. Vista parcial de San Martín de los Andes y lago Lácar, c.1940.

Fuente: Archivo Visual Patagónico. Fotógrafo Bruno Sálamon https://www.flickr.com/photos/archivovisualpatagonico/33256161181/in album-72157677820519624/.

En cuanto a la promoción específicamente creada para el PNL y de San Martín de los Andes, la producción de material por parte de la Dirección no es abundante. En realidad, la DPN se centraba en fomentar el interés por los parques nacionales en su conjunto o bien por promocionar los atractivos del más importante de ellos, el Parque Nacional Nahuel Huapi. El Lanín, en cambio, tenía un lugar secundario. Sin embargo, por su ubicación aledaña al anterior y sus características fisonómicas similares, tanto este como el Parque Nacional Los Alerces -localizado sobre la zona cordillerana de la provincia de Chubut, al sur del Nahuel Huapi- se vincularon de forma estrecha a él. Los tres respondían a una configuración paisajística específica identificada como los "lagos del sur". La denominación no era nueva, aunque su aplicación a toda esta sub-región con un sentido turístico está estrechamente vinculada al trabajo de Parques Nacionales. En una publicación de la Administración General de Parques Nacionales y Turismo (AGPNyT) de 1950, algunas fotos de San Martín de los Andes y el área del Lácar aparecen entremezcladas con las descripciones de la zona del Nahuel Huapi, mientras el foco de interés está siempre en el lago como elemento natural central de estos lugares. El tono de la descripción sigue la lógica poética a la que hemos hecho referencia:

Después de hecha la Tierra, Dios pensó que sería bueno que hubiera en ella algo en lo cual los cielos pudieran mirarse. Y buscó, así, sitios privilegiados en donde ubicar estas maravillas. Fue de ese modo que aparecieron esas obras maestras de la naturaleza que son los lagos montañeses en que se hermanan la cumbre y la estrella. No hay necesidad de decir que queremos referirnos a los Lagos del Sud. ${ }^{61}$

${ }^{61}$ Administración de Parques Nacionales y Turismo, Visión de Argentina (Buenos Aires: Ministerio de Obras Públicas de la Nación, 1950) 68. 
Parques Nacionales y la configuración de un destino turístico: transformaciones socio...

Así, podemos observar cómo se fue construyendo una idea de paisaje natural asociada a los parques nacionales, y la relevancia que iban adquiriendo ciertos centros urbanos como lugares turísticos. Mientras que alrededor de los primeros se iba generando una cierta imagen y se materializaba su atractividad, los segundos eran necesarios para consolidar aquello que no podía situarse en la naturaleza regulada, es decir, los servicios y la estructura para el funcionamiento de un destino turístico en construcción.

\subsection{La naturaleza como recurso. Medidas para la conservación de un paisaje "virgen"}

La puesta en valor de esa escenografía "natural" en los parques nacionales como atractivo implicaba, además de su valorización y promoción, la implementación de medidas para conservar sus características específicas, principalmente, la idea de una naturaleza virgen o inalterada. ${ }^{62}$ Específicamente, se establecía como prioridad el cuidado de bosques mediante la incorporación de normas para regular las actividades que se pudieran realizar dentro de la jurisdicción del parque. Cabe señalar que, en la definición de la "naturaleza" de la región, el bosque era un componente fundamental, para lo cual no solo se buscaba cuidar su integridad en determinados sectores, sino incluso "recomponerlo" en aquellos casos que se estimara necesario. ${ }^{63}$ La introducción de especies exóticas no estaba descartada y, de hecho, se establecieron estaciones para la experimentación que pudieran servir a dicho propósito. El caso más conocido es el de la Estación Forestal Isla Victoria -en el Parque Nacional Nahuel Huapi-, donde la selección de las plantas con las que se trabajaba se realizaba con criterios utilitarios, principalmente en función a los diferentes objetivos de Parques, ya fuera reforestación, ornamentación de calles o espacios públicos, así como uso en cercos privados, entre otros. En este sentido, Núñez y Núñez afirman que las referencias biológicas que aparecían allí eran más "excusas” que un objetivo en sí mismo y que, en cambio, lo que resulta interesante del funcionamiento de estos espacios es el modo en el que se definía el recorte de lo que era la "naturaleza que se cuida". ${ }^{64}$ En el caso del Parque Nacional Lanín, este contaba también con un espacio para este tipo de estudios aplicados; la Estación Pucará se encontraba muy cerca del límite de Chile, en un área dedicada a la explotación forestal desde inicios de siglo.

La creación del Parque Nacional Lanín implicó, primero, la delimitación de una extensa porción de territorio en el centro-sur neuquino que quedó bajo jurisdicción de la DPN. Aunque las actividades de explotación no fueron completamente prohibidas en su interior, se clasificaron sus tierras según el nivel de restricciones que regían para cada área, como hemos visto en el apartado anterior. Aunque la Colonia Maipú quedó clasificada como área de explotación conservativa, todo el parque fue declarado zona

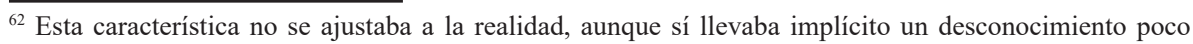
inocente, cuando no rechazo explícito, de la presencia de población indígena o criolla que vivía en la zona.

${ }^{63}$ Paula Núñez y Martín Núñez, "Naturaleza construida. Una revisión sobre la interpretación del paisaje en la zona del Nahuel Huapi” (3eras Jornadas de Historia de la Patagonia. San Carlos de Bariloche, noviembre 2008)

${ }^{64}$ Paula Núñez y Martín Núñez 8.
} 
no apta para el pastoreo, motivo por el cual la tenencia de ganado fue especialmente controlada.

La perspectiva general de las autoridades del Parque era que la población de la zona afectaba seriamente la regeneración natural de los bosques por el pastoreo "incontrolado" de sus animales, lo cual significaba un obstáculo para la conservación de la naturaleza. En 1940, con el fin de evitar este efecto negativo, el entonces Jefe del Servicio Forestal de la Reserva Lanín, Otto Neumeyer, presentó un proyecto en el que se buscaba "[...] facultar a la Intendencia para poder intervenir y desalojar sin más trámite el ganado que se encuentre en el bosque, aplicando multas, solicitar la cooperación de la policía y fijando otras normas que son del caso". ${ }^{65}$ El reglamento finalmente aprobado prohibía la tenencia de ganado, pero con algunas aclaraciones. El control de la hacienda en el parque no tenía como finalidad una completa interrupción de su presencia en las áreas rurales, sino que se pretendía ejercer una regulación de su cantidad y ubicación. La prohibición recaía sobre animales cuya presencia no estuviera autorizada previamente por Parques Nacionales, para lo cual se contaba con la extensión de permisos de pastaje en los que se establecía la cantidad de ganado mayor o menor que podía introducir un poblador en las tierras que ocupaba. La caída en la cantidad de cabezas de ganado en el Departamento Lácar entre los censos de 1937 y 1947 podría asociarse parcialmente al inicio de los controles ejercidos en la zona del área protegida. Sin embargo, se debe relativizar en un marco de caída en el promedio del Territorio neuquino, lo cual indica una baja general de esta actividad en la región. ${ }^{66}$

En cuanto a la explotación forestal, las medidas y apreciaciones realizadas por personal de Parques resultan un poco más ambiguas. Se creó el Servicio Forestal con el objetivo de organizar la regulación de la actividad maderera en la zona y se procedió a tomar las solicitudes hechas por pobladores y aserraderos locales. Las áreas de mayor explotación estaban ubicadas en las cuencas de los lagos Quillén, Lolog y Lácar. En particular, la zona del "Ensanche Oeste" de la Colonia Maipú se destacaba por la intensidad de la explotación. Mensurada en 1915 y declarada como área de reserva para explotación forestal en 1917, había sido foco de gran actividad antes de su entrada a la jurisdicción de Parques Nacionales. A diferencia de los lotes pastoriles de la Colonia Maipú, los del Ensanche Oeste tuvieron menor movimiento en cuanto a permisos de ocupación o aprobaciones de arrendamientos, en cambio, se

\footnotetext{
${ }^{65}$ Archivo Central de la Administración de Parques Nacionales, Expediente Nº5843/1940.

${ }^{66}$ Desde la introducción de medidas aduaneras en la década de 1920 pero, sobre todo, durante las décadas de 1930 y, fundamentalmente de 1940, se produjeron algunos cambios importantes que llevaron a que la actividad ganadera en Neuquén se fuera integrando al mercado nacional, produciéndose una ruptura con la historia de dinámica de complementación con la economía trasandina (Susana Bandieri "Actividades económicas y modalidades de asentamiento", Susana Bandieri y otros (eds.), Historia de Neuquén (Buenos Aires, Plus Ultra, 1993) 147-261. La presión del sector ganadero del vecino país fue otro factor que influyó en este sentido. (Fabián Almonacid "Comercio entre Chile y Argentina en la zona sur, en el contexto de una economía regional agropecuaria (1930-1960)" Pedro Navarro Floria y Walter Del Río (comp.) Cultura y espacio: Araucanía-Norpatagonia. Bariloche; Universidad Nacional de Rio Negro, Instituto de Investigaciones en Diversidad Cultural y Procesos de Cambio, 2011). El cierre progresivo de la frontera para la comercialización fue acompañado por un mayor control en el territorio, reforzado por la creación de la Gendarmería Nacional (1938) y su arribo a San Martín de los Andes en 1942.
} 
Parques Nacionales y la configuración de un destino turístico: transformaciones socio...

destaca la presencia de frecuentes solicitudes para explotación de los bosques fiscales allí ubicados. ${ }^{67}$

Los permisos se otorgaban, principalmente, a propietarios de aserraderos localizados en el área, en cuyo caso se aclara que se realiza el corte "para comercio" o "para industrialización”. Otros pedidos más acotados eran presentados directamente "para introducir mejoras" en los solares de San Martín de los Andes. Además de actores particulares, instituciones gubernamentales también solicitaban extraer maderas, principalmente para construcciones en el pueblo. ${ }^{68}$

Al crearse la Reserva, la DPN ordenó el estudio de los bosques con el objetivo de determinar las posibilidades de dar continuidad a la explotación. Los resultados de los informes indicaban que, dadas las condiciones en las que se encontraban las masas boscosas, "[...] no se trata más de la conservación de la naturaleza primitiva; el problema se presenta bajo otro aspecto: ¿cómo remediar el mal ocasionado por una mala administración anterior?". ${ }^{69}$ A pesar de este diagnóstico poco optimista, el otorgamiento de permisos no tuvo un fin abrupto, aunque sí se introdujeron nuevas medidas para controlar el modo de explotación forestal. Como resultado de los estudios realizados, se concluyó que el área del lago Lácar podía continuar siendo explotada, ya que sus bosques no tenían más el carácter de una "naturaleza intacta". Un dato interesante sobre los informes técnicos elaborados, es que se entremezclaban constantemente los criterios conservacionistas desde un punto de vista más científico y posturas más claramente elaboradas desde la importancia de la naturaleza como recurso turístico. Incluso se incorporaban percepciones sumamente subjetivas en las que la naturaleza aparecía abordada más desde la estética que desde lo científico:

Para mí la belleza de una naturaleza virgen tiene un valor absoluto, tanto estético como moral. Es como una sinfonía, y como no se puede sacar de una sinfonía algunas de sus partes sin destruir toda la obra, así la naturaleza virgen no puede ser alterada sin destruir todo su encanto. ${ }^{70}$

En el mismo informe se observa con particular detalle, por ejemplo, la ausencia de caña colihue que, en vez de ser una condición favorable para la explotación, era señalada porque permitía el paseo por el bosque; los claros y pampas, por otro lado, no eran solo el lugar para los renovales, sino lugares desde donde "admirar el panorama del lago y el cono majestuoso del Lanín”71. En otras palabras, aparecía

\footnotetext{
${ }^{67}$ Los permisos para explotar los bosques fiscales eran otorgados, primero, por la Dirección de Tierras y después por la DPN/AGPNyT. Pero todos pedidos fueron registrados en las fichas de lotes elaboradas posteriormente por la AGPNyT. De los 16 lotes con los que contaba, muy pocos fueron concedidos en arriendo a particulares y, cuando lo fueron, las concesiones realizadas acabaron durante los primeros años de la década de 1940. (Archivo de la Dirección Nacional de Conservación de Áreas Protegidas, Programa Pobladores y Comunidades, Administración de Parques Nacionales).

${ }^{68}$ Por ejemplo, la Gobernación de Neuquén pidió en 1937 extraer 500 toneladas de rollizos de raulí (libre de derechos) para construir las dependencias policiales en San Martín de los Andes.

${ }^{69}$ Nicolás Lebedeff, Informe preliminar sobre los estudios de los bosques en la Reserva “Lanín” (1942) 8.

${ }^{70}$ Nicolás Lebedeff 136.

${ }^{71}$ Nicolás Lebedeff 137.
} 
constantemente, en un mismo nivel que la conservación ambiental, el deseo por una preservación estética de la escenografía bajo la cual afianzar una actividad turística.

\subsection{Primeros pasos para la adecuación del espacio turístico}

Las primeras acciones tendientes a la adecuación del espacio para la actividad turística se orientaron hacia dos fines. Por un lado, era necesario asegurar el acceso a la zona, objetivo no menor teniendo en cuenta la marginalidad de la región. Por el otro, la provisión de servicios turísticos se centró, al menos en este primer momento, en el alojamiento.

Las vías de acceso hacia la zona dependían directamente de la conexión con el Parque Nacional Nahuel Huapi. Allí, la llegada del ferrocarril en 1934 había solucionado el importante problema de la conectividad con Buenos Aires, centro del mercado turístico nacional. Existía otra vía para acceder a San Martín de los Andes, mediante la ruta que la unía con Junín de los Andes y, desde allí, con Zapala, punta de rieles desde 1913. Sin embargo, al menos para la actividad turística, se priorizó el vínculo con Bariloche. Durante los primeros años de existencia del PNL, casi la totalidad de sus visitantes llegaban por esta vía (en general se trataba de una excursión por el día). En este sentido, la cercanía con ese parque era una ventaja. ${ }^{72}$

El progresivo avance de caminos que interconectaran los diferentes atractivos bajo jurisdicción de la DPN puede comprenderse mejor si se atiende al diseño de la red de villas turísticas que funcionaban como "satélites" de los diferentes parques. En el área que va del Nahuel Huapi a la zona del lago Lácar, una serie de asentamientos de este tipo localizados a lo largo de la cordillera proveían esa continuidad entre las dos áreas protegidas: Villa la Angostura, Villa Traful y Villa Quila Quina. Estas villas eran valoradas como "[...] focos de irradiación nacional y como centinelas efectivos de $[\ldots]$ soberanía $[. .$.$] ". { }^{73}$ Además, consideramos que la introducción de nodos de "urbanidad" en un marco de grandes extensiones de superficie intocable (espacio de ocio no mercantilizado) adquiría otra importancia, porque se abrían como nuevos espacios complementarios necesarios para el turismo. En cuanto a la posibilidad de conectarlas entre sí, esta era una labor nada fácil. Sin embargo, huellas o caminos rudimentarios que unían algunas estancias entre sí o con los centros urbanos más cercanos fueron aprovechándose para delinear conexiones entre diferentes sectores del parque que se iban integrando como puntos a visitar.

La construcción de nueva infraestructura era una necesidad para la refuncionalización del espacio e incluía no solo caminos, sino muelles, puentes y otras

\footnotetext{
${ }_{72}$ Según la Memoria oficial de Parques de 1940, "Del 30\% de turistas que proyectaban salir [de Buenos Aires] en automóvil, un 20\% incluía en sus itinerarios sendas visitas al Lago Nahuel Huapi y Reserva Nacional Lanín y el 10\% restante, a la Reserva Nacional Los Alerces en la temporada 1939-1940. Durante la temporada 40-41 la proporción aumentó a 25\% y 15\% respectivamente" Dirección de Parques Nacionales, Memoria correspondiente al año 1940 (Buenos Aires: Ministerio de Agricultura de la Nación, 1941) 70.

${ }^{73}$ Ezequiel Bustillo 196.
} 
Parques Nacionales y la configuración de un destino turístico: transformaciones socio...

obras que requerían un esfuerzo especial en zonas rurales de difícil acceso. Desde la mirada de la DPN, este trabajo era representado como empresa de colonización y domesticación de una naturaleza en estado salvaje:

La naturaleza estaba, radiante, desde los siglos y milenios. Pero hubo que vestir el paisaje, sin desnaturalizarla; facilitar el acceso a su contemplación. Caminos y puentes, muelles y atracaderos, viveros y estaciones zoológicas para la conservación de la flora y la fauna autóctonas; hoteles y hosterías. Estos trabajos, a tales distancias y soledades, en aquellas alturas y climas, exigen esfuerzos que el turista no se imaginará nunca $[\ldots]^{74}$

Las tareas de adecuación del espacio tenían como objetivo, a la par de posibilitar la circulación, permitir el desarrollo de nuevas actividades de ocio. Los paseos, excursiones, prácticas deportivas y otras formas de disfrute no podían realizarse sin la provisión de estas mejoras. La construcción de muelles y la introducción de embarcaciones fue una tarea encarada desde el inicio por la DPN. Los paseos por los lagos constituían una de las principales actividades turísticas en la zona. Desde San Martín de los Andes, lugar de asiento de la Intendencia del parque, se realizaban navegaciones por el lago Lácar, desde el muelle del pueblo hasta la recientemente creada Villa Quila Quina, y a Hua Hum, en el lago Nonthué. Esta última zona sobre el límite con Chile (Fig.4) coincidía con el circuito de mercantilización señalado para el período de inicios de siglo, así como el área de explotación maderera por excelencia. Por lo tanto, la navegación hacia allí no fue impuesta por la actividad turística, aunque sí resignificada por ella.

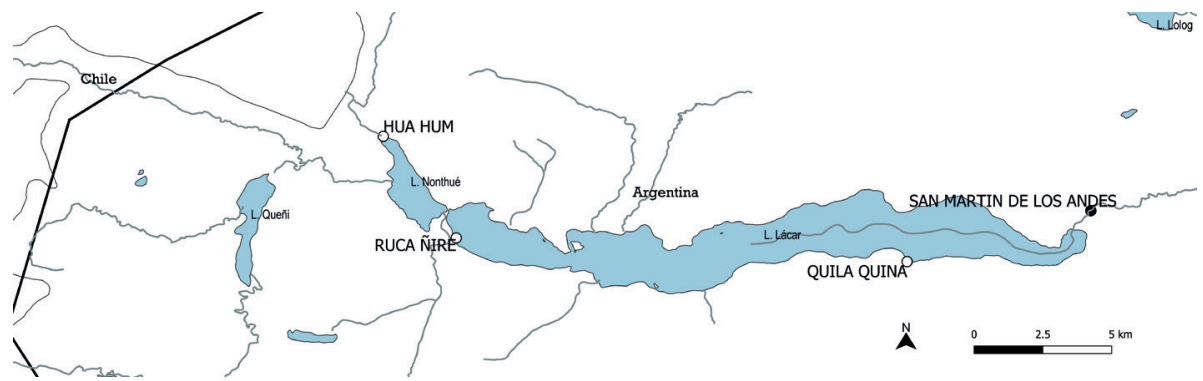

Figura 4. Cuencas de lagos Lácar, Nonthué y Queñi.

Fuente: elaboración propia.

Además de las excursiones, los lagos y los ríos eran lugares para practicar la pesca. Sin embargo, para ello eran necesarias otro tipo de intervenciones, como se sostenía cuando, en 1946, se hacía referencia a las dificultades para el acceso a lagos por la ausencia de vías terrestres y de hospedaje en ellos, todo lo cual constituía un problema para el desarrollo de ese deporte. ${ }^{75}$ Durante los años 40 se produjeron también

\footnotetext{
${ }^{74}$ Administración de Parques Nacionales y Turismo, Memoria correspondiente al año 1947 (Buenos Aires: Ministerio de Obras Públicas de la Nación, 1948) 40.

${ }^{75}$ Administración de Parques Nacionales y Turismo, Memoria correspondiente al año 1946 (Buenos Aires: Ministerio de Obras Públicas de la Nación, 1947).
} 
los primeros pasos para la introducción del esquí como parte de las actividades que podrían realizar los visitantes del PNL; sin embargo, esta actividad estaba apenas en una etapa inicial y, durante el período que nos ocupa, el esquí no alcanzó a constituir aún una oferta consolidada que pudiera movilizar un flujo de turistas en la temporada invernal. ${ }^{76}$

Los trabajos requeridos para crear los espacios e instalaciones complementarias necesarias para hacer posible la práctica turística eran, como hemos señalado hasta aquí, numerosos y variados. Es posible afirmar que, al menos en este primer momento, las exigencias más urgentes estaban asociadas a la provisión de instalaciones hoteleras. En las memorias de la DPN, esta necesidad aparece constantemente como la principal dificultad para poder consolidar a San Martín de los Andes como destino, teniendo en cuenta que la mayor parte de los primeros visitantes eran pocos y venían "de paso" desde Bariloche. Para superar esta condición, era importante que hubiera servicios de hospedaje adecuados. Desde la dependencia estatal se buscó dar solución a esta demanda no solo mediante la construcción de alojamientos por cuenta propia, sino también con el otorgamiento de créditos para la inversión de privados. En cuanto a la ubicación, aunque la posibilidad de hospedarse dentro de las áreas rurales del Parque era deseable, la construcción de hoteles allí era dificultosa; la concentración de la edificación se terminó concentrando en la zona urbana.

Si se comparan las recomendaciones y proyectos en la documentación producida durante el período de creación del área protegida y lo que finalmente se logró materializar durante los años siguientes, se aprecia un desplazamiento de los lugares de interés dentro del extenso territorio del Parque. En un primer momento, se sostenía la importancia de desarrollar un "troncal longitudinal norte-sur", que se basaba probablemente en la importancia del que, en ese momento, se consideraba el principal atractivo: el volcán Lanín (cerca de Junín de los Andes). Sin embargo, el área que terminó concentrando la mayor parte de las intervenciones fue la cuenca del lago Lácar, es decir, la zona de influencia de San Martín de los Andes, sede de la Intendencia. ${ }^{77}$

\footnotetext{
${ }^{76}$ En Bariloche se construyó en aquellos años el Cerro Catedral, obra que requirió de una gran inversión. San Martín de los Andes, en cambio, no tuvo un centro de esquí hasta la década de 1970; sin embargo, la DPN llevó en este período instructores especializados que impartían sus clases sobre las laderas de los cerros.

${ }^{77}$ En el informe de la exploración realizada en 1936 para la creación de la Reserva se había confeccionado un listado con las ubicaciones recomendadas para la construcción de hoteles. Los puntos referidos en aquel estudio eran las termas de Epulafquen y el lago Tromen, en el Departamento de Huiliches; y el sur del lago Quillén y los lagos Rucachoroi, Ñorquinco y Moquehue en el Departamento de Aluminé. Finalmente, las prioridades no estuvieron puestas en estos lugares y, de hecho, en ninguno de ellos se alcanzó a construir hotelería durante este primer período. En cambio, para fines de los cuarenta funcionaban dos hoteles bajo administración de Parques Nacionales, ambos en el Ensanche Oeste de la Colonia Maipú, es decir, sobre las costas oeste del lago Lácar y las del lago Nonthué. Esta zona estaba mucho más fácilmente conectada con San Martín de los Andes que las anteriores y coincidía con el circuito lacustre más promocionado dentro del parque. Dirección de Parques Nacionales, Nuevos Parques Nacionales. Proyecto de Reservas para la creación de Parques Nacionales en los Territorios Nacionales del Neuquén, Chubut y Santa Cruz (Buenos Aires: II ${ }^{\mathrm{a}}$ ed., s.f. [1937]).
} 
Dentro de los circuitos trazados por la DPN y, particularmente, dentro del pueblo, algunos actores empezaban a insertarse en la incipiente economía turística a través de la oferta de servicios asociados, principalmente en el sector de alojamiento. Antes de la creación del PNL, existían en la zona unos pocos establecimientos para el hospedaje de viajeros. En Hua Hum (fig.4), la hostería Rozemburg -localizada en la zona de Nonthué- ofrecía alojamiento a quienes transitaban por ese paso, que era una de las principales rutas comerciales durante los primeros años del siglo XX y unía a San Martín de los Andes con ciudades del sur chileno. En la planta urbana, un hotel y algunas pensiones servían de hospedaje para migrantes recién llegados, principalmente maestros, misioneros o miembros del ejército y gendarmería, así como para estancieros y administradores de estancias que realizaran transacciones en los almacenes de ramos generales u otros trámites en el pueblo. ${ }^{78}$

Un caso diferente fue el del Hotel Los Andes, construido en 1938 por Guy Dawson en San Martín de los Andes con un préstamo de la DPN. Fue uno de los primeros con una finalidad claramente turística desde su proyección. Estaba ubicado en un predio de 21 hectáreas dentro del ejido urbano, a orillas del arroyo Trabunco, lo cual permitía a su propietario ofrecer salidas de pesca con mosca, actividad en la que destacaba. ${ }^{79}$ En las afueras del pueblo, a pesar de las dificultades, hubo unos pocos proyectos que se llevaron a cabo. Un ejemplo paradigmático es la casa de té y hospedaje Arrayán, inaugurada a fines de la década de 1930 sobre la ladera de una montaña a pocos kilómetros del casco urbano, con vista al lago Lácar. Para su construcción se necesitó transportar maderas que provenían de Ruca Nire, sobre el lago Nonthué, a través de la navegación.

La mayor parte de la capacidad hotelera se instaló en la ciudad. En 1946, casi diez años después de creado el PNL, se habían hospedado en él cerca de 4.000 turistas, de los cuales más de dos tercios lo hicieron en San Martín de los Andes. La cifra es muy pequeña, si se la compara con los visitantes que recibió el vecino parque Nahuel Huapi durante el mismo período, alrededor de 17.000 personas. La capacidad hotelera era todavía escasa y su insuficiencia se sentía especialmente durante los meses de enero y febrero, época en la que arribaba la mayor parte de turistas a la zona. ${ }^{80}$

Además del alojamiento, había una variedad de actividades en las que se iban insertando diferentes actores para complementar la oferta administrada directamente por Parques. Algunos ejemplos son el caso mencionado de Guy Dawson, quien operaba como guía de pesca. En cuanto a las excursiones lacustres, aunque la AGPNyT contaba con embarcaciones propias que realizaban el circuito a Quila Quina y Hua Hum, ello no impedía la creación de nuevas empresas dedicadas a estos paseos.

\footnotetext{
${ }^{78}$ M. Graciela Maragliano, Hotel Lácar: 100 años en la vida de San Martín de los Andes (Córdoba: Ferreyra Editor, 2010) 35.

${ }^{79}$ René Gingins y otros San Martín de los Andes. Pueblo + Arquitectura (San Martín de los Andes: el autor, 2014).

${ }^{80}$ Administración de Parques Nacionales y Turismo, Memoria correspondiente al año 1947 (Buenos Aires: Ministerio de Obras Públicas e la Nación, 1948) 27.
} 
Bruno Salamon es señalado como uno de los primeros en incursionar desde el ámbito privado, su servicio lacustre recibía “contingentes a través de la Empresa Exprinter, erigiéndose así en el primer agente receptivo de turistas" ${ }^{81}$ Los locales gastronómicos también formaban parte de estas primeras actividades asociadas a la nueva economía de la zona.

Sin embargo, los emprendimientos de este tipo no fueron muchos, teniendo en cuenta que la cantidad de visitantes en el parque todavía era poco significativa. De todos modos, los cambios en la economía podían resultar dinamizadores de otras actividades no necesariamente vinculadas de forma directa al turismo, aunque se vieran beneficiadas por este sector. El crecimiento de la actividad comercial durante este período podría estar dando cuenta de ello, aunque no se debiera únicamente a la presencia de visitantes sino también como producto de una población en aumento que se iba concentrando en el casco urbano. ${ }^{82}$

\section{La reconfiguración económica y urbana de San Martín de los Andes}

Al acercarnos a la mitad del siglo XX es posible ir viendo una serie de cambios en la zona del Parque Nacional Lanín. De lo expresado en los apartados anteriores se desprende que el impacto de las acciones sobre el territorio se iba materializando de forma particular en San Martín de los Andes. En esta sección, nos detendremos en las modificaciones sobre el espacio construido en la planta urbana, enfocándonos específicamente en el crecimiento de la ciudad y en el modo en el que influyó la DPN/AGPNyT en este proceso, teniendo siempre como eje la refuncionalización del espacio para la actividad turística.

La década de 1940 estuvo marcada por el final de la gestión de Bustillo (1944) y el cambio en la denominación de la antigua Dirección como Administración General de Parques Nacionales y Turismo (AGPNyT), que pasó a depender del Ministerio de Obras Públicas (1945). La llegada del peronismo al poder implicó una serie de cambios en las políticas de Parques, así como en el contexto políticosocial en general. Por un lado, un hecho significativo del período fue el despliegue

\footnotetext{
${ }^{81}$ A. M. de las Nieves Aquín de Capiet, "El Turismo. San Martín de los Andes se abre al país y al mundo", Comisión del Centenario y Fundación San Martín de los Andes.

${ }^{82}$ Durante inicios del siglo, la importancia de la economía agropecuaria en la zona iba de la mano de un nivel de intercambios comerciales de importancia relativa dentro de la dinámica del Territorio neuquino. Para contextualizar el crecimiento de la actividad comercial en la zona, resulta relevante la comparación con sus jurisdicciones vecinas, los Departamentos Huiliches y Los Lagos, entre los censos de 1920 y 1947. En este último, llama la atención el aumento de las casas comerciales, que pasaron de 3 a 24, registrando el mayor crecimiento del Territorio. Esto contrasta con el caso del Departamento Huiliches, que a pesar de duplicar esa cantidad en el censo, estuvo por debajo del promedio del Territorio y fue uno de los Departamentos que menos incremento registró en este sentido. Sin querer caer en explicaciones monocausales, consideramos que esta diferencia podría explicarse, en parte, por el impulso dado por la actividad turística a la zona. Por un lado, la creación del pueblo de Villa la Angostura - como parte del plan de villas turísticas, dependiente en este caso del Parque Nacional Nahuel Huapi- podría explicar el aumento de actividad comercial en el Departamento Los Lagos del que es cabecera. Huiliches, en cambio, no tuvo un crecimiento marcado de su actividad comercial, que continuaba dependiendo principalmente de la actividad ganadera.
} 
de políticas para la introducción del turismo social, con el objetivo de implantar un turismo popular en Argentina. ${ }^{83}$ Por otro lado, durante esos años, como señala Núñez, el cambio político tuvo implicancias en la mirada sobre la frontera, particularmente sobre la relación entre "lo nacional" y el vínculo con Chile. ${ }^{84}$ Además, siguiendo a la misma autora, el reclamo por la ampliación de derechos ciudadanos en este contexto histórico tuvo, en el sur del país, características regionales y locales específicas (y diferenciadas en cada caso). En este sentido, la coyuntura de aquellos años ameritaría una profundización en el estudio de las políticas y los conflictos locales - tal como se ha hecho en el caso de Bariloche- para repensar la historia de San Martín de los Andes.

Durante el período que abordamos, el aumento poblacional de la región fue de la mano con una concentración en la zona urbana de San Martín de los Andes, que pasó de tener 789 habitantes, en 1912, a 2.336 en $1947 .{ }^{85}$ La concentración en el pueblo era un objetivo deseado por la DPN/AGPNyT. A pesar de que no se definiera explícitamente como tal, podemos rastrear cierta política demográfica en el accionar de la dependencia durante el período estudiado. Como hemos señalado anteriormente, la población rural era percibida como indeseable. Los controles y el uso de la fuerza pública era una constante para controlar las presencias indeseadas. Identificamos diferentes ejes argumentativos mediante los cuales se justificaba un estricto control sobre ella.

El primer argumento que encontramos es aquel que justifica, bajo la supuesta amenaza a la naturaleza, la necesidad de intervenir. ${ }^{86}$ Además del control sobre la hacienda, se implementaron medidas que afectaban directamente a sus poseedores, principalmente, mediante desalojos, traslados y concentración en espacios destinados a ello (como la ex estancia Pulmarí, expropiada en 1948 con esa finalidad). A los fines "conservacionistas" se sumaba como fundamento la preocupación geopolítica. Un segundo eje, entonces, se traza por la creación "zonas de seguridad fronteriza" en la década de 1940, que implicó que los pobladores necesitaran contar con permisos de radicación para permanecer en el área. La condición de extranjeros de algunos de ellos justificó la expropiación de sus campos, como el caso de la familia Van Dorsser de origen bóer. Algunos lograron permanecer en las tierras de las que ya no eran propietarios (cambiando sus principales actividades económicas), mientras que para otros significó directamente el traslado o desalojo forzoso. Un tercer argumento que encontramos se centra en las características de población rural en cuanto a sus condiciones de existencia. Desde esta perspectiva, el mejoramiento de la calidad de vida debía solucionarse mediante su traslado hacia zonas urbanas, en este caso, hacia la localidad de San Martín de los Andes:

\footnotetext{
${ }^{83}$ Elisa Pastoriza 197.

${ }^{84}$ Paula Núñez, "La incompleta re-construcción peronista de la frontera: Un análisis desde la región del Nahuel Huapi, Argentina (1946-1955)" Estudios Fronterizos 16.31 (2015) 100

${ }^{85}$ Censo de Territorios Nacionales (1912) y Censo Nacional (1947).

${ }^{86}$ Administración General de Parques Nacionales y Turismo Memoria correspondiente al año 1945 (Buenos Aires: Ministerio de Obras Públicas de la Nación, 1946) 50.
} 
Toda la población, excepto la establecida con derechos en San Martín de los Andes, está irregularmente distribuida por las 395.000 hectáreas del Parque, viviendo en un bajísimo nivel y deplorable estado moral, higiénico y sanitario. De ahí la insistencia con que la Intendencia del Parque Nacional Lanín vuelve a plantear la iniciativa de concentrar a todos los pobladores de la extensa región en las inmediaciones de San Martín de los Andes (Colonia Maipú), dotándolos de viviendas adecuadas. Se facilitarán así las oportunidades de trabajo, se asegurará la educación de sus hijos, y se logrará en general, elevar su nivel de vida. ${ }^{87}$

En resumen, las medidas implementadas en términos demográficos se orientaron fundamentalmente a concentrar la población en la localidad de San Martín de los Andes, mientras se buscaba disminuir todo lo posible a aquella asentada en las áreas rurales. Pero, para avanzar sobre esta concentración, era necesario dotar al pueblo de infraestructura necesaria para que alojara a los habitantes de la región en condiciones adecuadas para que residieran y contribuyeran con su fuerza de trabajo a la nueva economía turística que se estaba buscando implantar. Por ello, la DPN/ AGPNyT tuvo un rol importante no solo en el cuidado de bosques y lagos de la región, sino que cobró una relevancia especial en materia de equipamiento de las nacientes ciudades patagónicas. ${ }^{88}$ Ya hemos mencionado brevemente el caso de Bariloche, principal objeto de intervención de esta dependencia.

En la ciudad de San Martín de los Andes, el principal objetivo era asegurar las condiciones necesarias para fomentar su crecimiento como principal centro urbano vinculado al PNL. Para ello, Parques Nacionales se involucró en la construcción, entre otros, del primer hospital, el correo y algunas escuelas, tanto en el centro como en algunos parajes rurales de la zona. Al mismo tiempo, debía llevar adelante obras para su propio funcionamiento (edificio de la Intendencia, casas para guardaparques y galpones). Y, finalmente, debía contribuir con la construcción de obras de uso turístico, como hemos adelantado en el apartado anterior. Todo ello confluyó en un papel central de la dependencia como principal impulsor de la construcción en la trama urbana.

A la influencia de Parques Nacionales en la concentración poblacional y su participación directa en la construcción de obras de uso colectivo, se sumó la adquisición de un rol importante en la regulación del crecimiento urbano de San Martín de los Andes en dos sentidos. Por un lado, el ofrecimiento de tierras fiscales dentro del ejido estuvo bajo su jurisdicción y, por otro, la imposición de determinados elementos arquitectónicos para la construcción mediante los reglamentos vigentes para el proceso de concesión de tierras y, también, mediante la erección de importantes edificaciones que resaltaban dentro del pequeño pueblo y que fueron marcando un estilo que se terminó por conformar en una marca identitaria local. ${ }^{89}$

\footnotetext{
${ }^{87}$ Administración General de Parques Nacionales Memoria correspondiente al año 1946 (Buenos Aires: Ministerio de Obras Públicas de la Nación, 1947) 79.

${ }^{88}$ En este punto es necesario recordar que, además de que tanto el pueblo como gran parte de sus alrededores estaban bajo su jurisdicción directa, el hecho de no haberse producido aún la provincialización de los territorios nacionales, éstos dependían directamente del poder central en Buenos Aires. Por lo tanto, la autoridad nacional era la fuente principal de las posibles planificaciones e intervenciones en este territorio.

${ }^{89}$ Gingins y otros 174 .
} 
El trazado del pueblo estaba organizado en quintas de una hectárea para la producción y en solares residenciales más pequeños (cuatro por cada cuadra de una hectárea). Las tierras fiscales que conformaban esta trama fueron siendo concesionadas, primero, por la Dirección de Tierras y, más tarde, por la DPN. En la década de 1940, esta elaboró, como dispositivo para consulta propia, una serie de fichas en las que se resumía la información de cada uno de los lotes sobre los cuales se registraban los arriendos, solicitudes de compra, emplazamientos para construcción, sucesiones y otros trámites. A partir de la indagación de estas fuentes, conocemos algunas características sobre cómo se fueron ocupando estos terrenos.

Durante las primeras décadas de existencia del pueblo, tanto quintas como solares fueron siendo rápidamente repartidas entre sus habitantes, que aumentaban año a año. A los antiguos pobladores de la zona y miembros del ejército con sus familias, se iban sumando los migrantes provenientes de diferentes lugares del país y del exterior. En 1930, la superficie total ocupada era considerable y quedaban para ese momento pocas fracciones sin adjudicación. Esto es más notorio en las manzanas de las quintas (diferenciadas de los solares por no tener subdivisiones internas). En este caso, la mayor parte de las adjudicaciones se realizaron durante 1924-1927, período en el cual la Dirección de Tierras otorgó 40 concesiones, de las que, en 1930, solo 3 habían sido escrituradas, mientras que la gran mayoría aún no cumplía con los requisitos para hacerlo. Los solares otorgados en concesión, en cambio, representaban una menor proporción sobre el total disponible; sin embargo, para ese año se habían escriturado varios de ellos, la mayoría en los alrededores de las plazas San Martín y Sarmiento. ${ }^{90}$

El aumento en la ocupación y construcción sobre los solares residenciales puede analizarse al comparar los ofrecimientos publicados por la Dirección de Tierras en 1933 y luego por la AGPNyT en 1949, momento en el que constata una importante disminución en la superficie disponible para la venta. La gran mayoría de los solares habían sido adjudicados, e incluso estaban ya escriturados. Aunque el período entre un ofrecimiento y otro es extenso, sabemos que ya finalizando la década de 1930 era notorio el aumento en la demanda de tierras en el pueblo. Una resolución de enero de 1937 establecía que, a partir de ese momento, las adjudicaciones se realizaban únicamente por medios solares, salvo alguna "excepción debidamente justificada". La limitación obedecía a "que existen escasos solares de propiedad fiscal y numerosos interesados por ellos". ${ }^{91}$ Las reiteradas subdivisiones de los lotes a lo largo de los años dan cuenta de esa alta demanda. Por otra parte, el significativo aumento de los

\footnotetext{
${ }^{90}$ Una acotación sobre el valor de los solares en el pueblo puede realizarse a partir de la información provista por el ofrecimiento de 1933 registrado en las fuentes, a partir del cual realizamos un mapeo de los solares ofrecidos ese año distinguiéndolos por su precio. El resultado muestra un comportamiento "típico" de los costos de la tierra para ciudades pequeñas, en las que el valor de los terrenos disminuye desde la avenida principal (Av. San Martín) hacia afuera, a medida que aumenta la distancia del centro. Los solares con frente sobre dicha calle eran los más caros, mientras que los restantes tenían precios cada vez más bajos mientras más se alejaran del centro, siguiendo como líneas de referencia las calles paralelas a la avenida principal.

${ }^{91}$ Archivo de la Dirección Nacional de Conservación de Áreas Protegidas, Programa Pobladores y Comunidades, Administración de Parques Nacionales (APN).
} 
lotes escriturados se puede asociar a un efectivo crecimiento en el espacio construido, teniendo en cuenta que la concesión de dichas tierras iba acompañada por la expresa obligatoriedad de levantar en ellas casas para habitar.

La intermediación estatal ejercida en el otorgamiento de solares por parte de la DPN/AGPNyT no es un dato menor, y podríamos considerarla, en cierto sentido, como complementaria a las políticas demográficas señaladas anteriormente. La intencionalidad dirigida a la concentración poblacional en el casco urbano en detrimento de las áreas rurales -y al mantenimiento de cierta "imagen" de esteestaba presente desde un primer momento. En la Memoria de la Dirección de 1939 se destacaban positivamente los resultados del último llamado a licitación:

La demanda superó las previsiones y, es de hacer notar la importancia de este detalle, ya que todos los solicitantes, sobrepasaron holgadamente los precios básicos. Otro detalle digno de considerarse es que las ofertas estaban condicionadas a la construcción de casas, dentro de plazos de un año para los solares y de dos años para las quintas con valores mínimos fijados para las construcciones cuyos planos deberán ser aprobados por la Repartición, lo que evidencia que los solicitantes presentados son personas de solvencia material. ${ }^{92}$

En general, las expectativas que se ponían sobre el desarrollo de la ciudad como lugar para el establecimiento de una población "civilizada" se acentuaban por la mirada sobre la población de la zona y el diagnóstico que se realizaba sobre sus condiciones materiales. En una conferencia realizada en Buenos Aires en 1936, el entonces intendente del Parque Lanín (Otto Neumeyer) señalaba que, en la zona cordillerana, la "típica" vivienda popular consistía en el

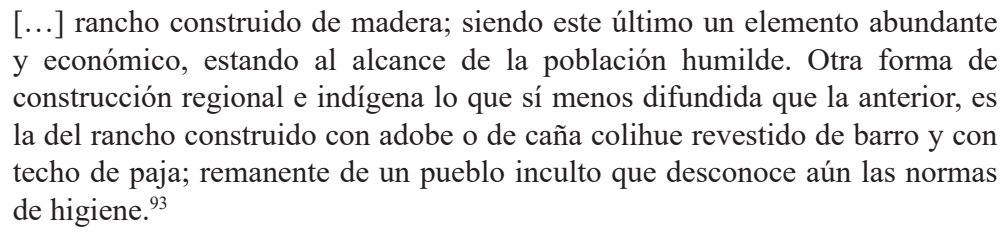

En cuanto a las características de las primeras casas construidas en la planta urbana, se destaca una "arquitectura del autoabastecimiento". 94 La función parcialmente productiva que adquirían las construcciones en este y otros pueblos de la Patagonia a principios del siglo pasado estaba asociada a las carencias que presentaba el sistema de comunicación con el resto del país y las condiciones climáticas que dificultaban aún más el vínculo con otros centros urbanos, todo lo cual hacía necesaria una producción mínima de alimentos para la subsistencia de los pobladores. Estas características fueron cambiando en la medida en que iba creciendo la cantidad de

\footnotetext{
${ }^{92}$ Dirección de Parques Nacionales, Memoria correspondiente al año 1939 (Buenos Aires: Ministerio de Agricultura de la Nación, 1940) 118.

${ }^{93}$ Otto Neumeyer, “Colaboración a la Conferencia Nacional de la Vivienda Popular: Región de Los Lagos, Territorio de Neuquén” (1936).

${ }^{94}$ Gingins y otros.
} 
Parques Nacionales y la configuración de un destino turístico: transformaciones socio...

construcciones por manzana, para dar cabida a una población en crecimiento. Sin embargo, la existencia de carencias en parte de la población era una preocupación para la DPN/AGPNyT. Su insistencia en la arquitectura doméstica se asocia, en parte, a las supuestas expectativas depositadas sobre el destino turístico en proceso de construcción:

Los intrusos de hecho, así como los intrusos de derecho, que vendrían a serlo los concesionarios en abierto incumplimiento con los compromisos contraídos, agregan a la belleza de la zona y muy especialmente, a la de San Martín de los Andes una nota triste de pobreza y miseria. Esta Intendencia interpretando los deseos de la Superioridad ha pretendido evitar la exhibición de esos cuadros dolorosos en lo que se quiere hacer un lugar de turismo conocido internacionalmente. ${ }^{95}$

La imagen de "aldea alpina" guiaba al mismo tiempo una serie de pautas a tener en cuenta, sobre todo en la edificación pública. A la necesidad de proveer de infraestructura se agregaba el interés por determinar el diseño de los principales centros urbanos que hacían de "puertas" a los parques. En Bariloche, la DPN llevó adelante, desde 1934, una verdadera refundación de la ciudad, a través de la concreción de una obra de planificación urbana sin precedentes en la Patagonia. El estilo creado por el arquitecto Alejandro Bustillo y su equipo se caracterizaba por el uso de madera y piedra, con una apariencia orientada a la idea de una "Suiza argentina" (como se identificaba a aquella zona). La jerarquización de esta arquitectura se lograba mediante la incorporación de grandes edificaciones, como el Centro Cívico o el Hotel Llao Llao. ${ }^{96}$

Esta forma de construir buscó replicarse a través de las intervenciones realizadas en la ciudad de San Martín de los Andes durante la década de 1940, que fueron otorgando una particular impronta a su pequeño casco urbano. La planificación de un Centro Cívico, aunque de menores dimensiones que el de Bariloche, buscaba un objetivo similar. A pesar de que no se pudo concretar por completo, en él se había

[...] proyectado ubicar distintos edificios, dependientes de diversos ministerios con el fin de centralizar las actividades cívicas del pueblo en base a un conjunto armónico. Se ha proyectado ubicar en él, los edificios para Escuela, Correos y Telégrafos, Juzgado de Paz, Aduana, Intendencia de Parques Nacionales y hoteles particulares. Enfrentando el Centro Cívico, la Iglesia como eje de composición urbanística. ${ }^{97}$

\footnotetext{
${ }^{95}$ Dirección de Parques Nacionales Memoria correspondiente al año 1941 (Buenos Aires: Ministerio de Agricultura de la Nación, 1940) p.118.

${ }^{96}$ Liliana Lolich ,"Los planes urbanos y su relación con el paisaje cultural en zonas de frontera. Caso Bariloche, Patagonia Argentina (1934-1979)", Paula Núñez (comp.), Miradas Transcordilleranas: Selección de Trabajos del IX Congreso Argentino Chileno de Estudios Históricos e Integración Cultural (San Carlos de Bariloche: IIDyPCa, UNRN-CONICET, 2011).

${ }^{97}$ Dirección de Parques Nacionales Memoria correspondiente al año 1941 (Buenos Aires: Ministerio de Agricultura de la Nación, 1942) 89.
} 
Esta planificación de 1941 no alcanzó a completarse durante la gestión de Bustillo, aunque se llegó a concretar la Intendencia y el edificio de Correo, ambos frente a la plaza principal. El primero resaltaba por sus dimensiones y diseño al lado de las pequeñas construcciones del pueblo. Contrastaba en particular con la pequeña sede de la Comisión de Fomento construida frente a la misma plaza en 1931. Como el Edificio Municipal se inauguró en 1959, durante casi veinte años, fue la dependencia del Parque y no del municipio la que destacaba como principal sede administrativa en la localidad, lo cual no es un dato menor. Además, según Gingins, Lovato y Solanas, desde un punto de vista arquitectónico, la construcción de la Intendencia y el trazado de la plaza constituyeron un punto de inflexión en la historia urbanística y arquitectónica del pueblo. ${ }^{98}$ A partir de estos años, algunas características de la arquitectura de Parques se replicarían en diferentes construcciones públicas y privadas, constituyéndose como parte de la identidad del pueblo de San Martín de los Andes.

En resumen, la configuración e imagen del pueblo en crecimiento eran estrictamente vigiladas por Parques Nacionales, como recurso central para el aprovechamiento del turismo, objetivo para el cual intervenía regulando las construcciones, así como erigiendo edificaciones que seguían un estilo arquitectónico particular.

\section{Conclusiones}

La creación de parques nacionales como áreas para la conservación de una naturaleza supuestamente inalterada estuvo asociada, desde la primera experiencia norteamericana a fines del siglo XIX, a procesos de configuración de lugares turísticos. En principio, la invención del concepto de parque nacional se dio en estrecha relación con la idea de preservación de escenarios "salvajes" fundantes de la Nación estadounidense. Este modelo fue replicado en todo el mundo, con mayor rapidez en países de características similares a este último. Canadá, Australia, Nueva Zelanda y Argentina tenían historias asimilables por su relación con los extensos territorios sobre los cuales estaban, en ese período, avanzando para su integración a sus respectivos Estados-nación. La creación de parques implicó una operación de selección y valorización de determinados elementos naturales que, en el caso argentino, fueron ubicados rápidamente en el sur, donde no solo se estaba dirimiendo su soberanía, sino que se encontraban algunas características físicas del entorno particulares, similares a las de los primeros parques en las Montañas Rocosas. La elección y elaboración de determinados paisajes en la definición de los parques nacionales tenía, entonces, un trasfondo simbólico y material asociado a la relación entre nación y territorio. Sin embargo, se constata asimismo un innegable vínculo entre éstos y el desarrollo de actividades turísticas, a pesar de que no se definieran de forma explícita desde el fundamento de su creación. La definición de estos lugares como espacios para el disfrute público puede entenderse, en este sentido, como punto de partida para el desenvolvimiento de estas actividades. La demarcación de territorios para visitar conllevaba el inicio de modificaciones en ellos y en sus alrededores, para conectarlos

${ }^{98}$ René Gingins y otros 148. 
y para adecuarlos a la llegada de los visitantes. Como señala Scarzanella para el caso argentino, el lugar simbólico de una naturaleza asociada a la Nación no permaneció inmutable en el tiempo. Si en el período de entreguerras viró a otro en el que la naturaleza aparecía “(...) como fuente de riqueza económica y no solo espiritual del país"99; en un período posterior, se materializó como “(...) un lugar de entretenimiento y disfrute popular (...)". ${ }^{100}$

A lo largo de este trabajo hemos indagado en algunas características del proceso de espacialización del turismo a partir de la creación de parques nacionales, centrándonos en el caso del Parque Nacional Lanín. La delimitación de esta reserva implicó una serie de transformaciones socioeconómicas y territoriales que posibilitaron la implementación de un modelo o estrategia particular de refuncionalización espacial, caracterizada por la necesidad de creación o consolidación de ciudades que funcionaran como espacios complementarios al parque, delimitado como el espacio de ocio en torno al cual giraba esta actividad. La actuación de la DPN/AGPNyT fue fundamental en este sentido, al sentar las bases para la conversión de San Martín de los Andes en un destino que hoy tiene amplio reconocimiento a nivel nacional e internacional.

En primer lugar, partimos del concepto de atractividad como resultado de un proceso social de producción de un lugar. La selección y valorización de determinados atributos físicos fue contribuyendo a la elaboración de una figura paisajística particular. En el marco de esta operatoria estuvo presente también la introducción de alteraciones planificadas y efectuadas sobre lo que se iba definiendo como un paisaje "natural". La introducción de especies exóticas tanto de plantas como animales es un ejemplo de ello. La idea de los "lagos del Sur" consistía en la conjunción de bosques, montañas y lagos en una composición que aludía a una imagen europea ya conocida por la elite argentina, además de encontrar ecos en los parques norteamericanos que le habían servido de modelo. Por otra parte, la forma de presentar al conjunto de parques patagónicos (Nahuel Huapi, Lanín y Los Alerces) como unidad paisajística no fue casualidad, teniendo en cuenta que las políticas de parques tenían una mirada regional.

En segundo lugar, fueron necesarios cambios materiales sobre el territorio. La delimitación de un espacio específico para el ocio iba de la mano de una serie de medidas para la conservación de dichos atributos, en este caso, una serie de regulaciones sobre actividades productivas que resultaran un obstáculo para mantener la naturaleza virgen idealizada como escenario para la visita turística. Por otra parte, esta requirió la generación de determinada infraestructura y servicios, localizados en espacios claramente diferenciados del parque natural. En este sentido, se propició el fortalecimiento de los pueblos ya existentes, al mismo tiempo que se buscaba crear otros. Estos no solo debían cumplir con requerimientos funcionales como la oferta de alojamiento, sino que tenían que adecuar su apariencia en una línea estética definida.

\footnotetext{
${ }^{99}$ Eugenia Scarzanella 6.

${ }^{100}$ Eugenia Scarzanella 7.
} 
Los requerimientos arquitectónicos iban acompañados de una constante preocupación por las condiciones de vida de sus habitantes, ya que uno de sus principales fines estaba asociado a concentrar a la población de la zona, cuya presencia en las áreas rurales del parque era vista como indeseable.

En tercer lugar, nos interesa remarcar que las intervenciones de la DPN/ AGPNyT en este caso de estudio formaron parte de una planificación regional, inaugurada en 1934 con la creación del vecino Parque Nacional Nahuel Huapi. Esa primera experiencia conllevaba una forma específica de vínculo entre el Parque y la ciudad de Bariloche, que fue tomada como modelo a replicar, en este caso, en la relación entre el Parque Nacional Lanín y San Martín de los Andes.

Consideramos que el estudio de este caso nos permite continuar reflexionando en torno a un vínculo particular que se traza entre áreas protegidas y localidades aledañas a ellas, en un contexto de fomento a la actividad turística. Esta última, como hemos visto, requiere y, a la vez, modifica el territorio sobre el que se realiza. Las observaciones realizadas por Sánchez para la dinámica territorializadora del turismo son pertinentes en este caso. Si bien el autor se detiene particularmente en el turismo de litoral, consideramos que, también en el caso de este turismo de montaña -con áreas naturales protegidas- se puede constatar una doble refuncionalización espacial en la que se distingue, claramente, entre un espacio de ocio no mercantilizado y otros espacios complementarios, necesarios para sostener la actividad.

En el caso del Parque Nacional Lanín, la doble territorialización conceptualizada por Sánchez adquirió características específicas. La valorización del entorno natural fue acompañada de una fuerte regulación de la población y de las actividades productivas en las áreas rurales, donde se procuraba mantener intacta la naturaleza virgen. Aunque el acceso al parque fuera público, una serie de servicios se fueron incorporando como mediadores a través de la mercantilización del tiempo de ocio. Es decir, que para el consumo turístico del recurso paisajístico se requirió la creación de nuevos espacios complementarios, concentrados en su mayoría en la zona urbana de San Martín de los Andes. El espacio social resultante fue adquiriendo, por lo tanto, nuevas características, diferentes a las que predominaban durante el período anterior a la creación del parque nacional. Las relaciones sociales de producción en las áreas rurales se vieron trastocadas por el ejercicio de un control que iba en aumento, particularmente por lo que significaba para los pobladores cuya reproducción social se basaba en la explotación de las tierras ya fuera para pastoreo o para cultivos de autoabastecimiento. Al mismo tiempo, el crecimiento urbano de San Martín de los Andes pasó a ser materia de estrategia política, cuyos criterios estaban orientados al fomento de la nueva actividad turística. Esta peculiaridad fue el resultado del rol central del Estado en este caso de estudio, en el que, actuando como administrador de los Parques Nacionales, ejerció una amplia capacidad en la planificación de este $-\mathrm{y}$ otros- destinos turísticos emergentes.

Como resultado de estos primeros años de intervención de la DPN/AGPNyT sobre el territorio, una porción de la región patagónica sufrió un viraje sobre las que 
habían sido, hasta el momento, algunas de sus principales características sociales y económicas. Se asentaron las bases para la consolidación de un turismo de naturaleza en estas zonas. Por supuesto no descartamos la existencia de tensiones e incluso resistencias de parte de diferentes actores locales (comunidades indígenas, autoridades, comerciantes, productores); sin embargo, el análisis en profundidad de estos aspectos requiere futuras indagaciones con nuevas fuentes documentales. Por otro lado, como hemos visto, el proceso de turistización a partir de la creación de parques nacionales no fue un fenómeno únicamente local, por lo cual sería interesante plantear a futuro estudios comparados, en especial con experiencias de otros países latinoamericanos.

\section{Bibliografía}

\section{Fuentes primarias}

Administración General de Parques Nacionales y Turismo Visión de Argentina (Buenos Aires: Ministerio de Obras Públicas, 1950).

Alberto De Agostini, El Lanín. Parque Nacional (Buenos Aires: S.E., 1941).

Bustillo, Ezequiel El Despertar de Bariloche. Una estrategia patagónica (Buenos Aires: Editorial y Librería Goncourt, 1968).

Dirección de Parques Nacionales Nuevos Parques Nacionales. Proyecto de Reservas para la creación de Parques Nacionales en los Territorios Nacionales del Neuquén, Chubut y Santa Cruz (Buenos Aires, II ${ }^{\mathrm{a}}$ ed. [1937]).

Dirección de Parques Nacionales (DPN)/ Administración General de Parques Nacionales y Turismo (AGPNyT): Memorias de los años 1935, 1937, 1938-1949.

Lebedeff, Nicolás Informe preliminar sobre los estudios de los bosques en la Reserva "Lanín” (1942).

Neumeyer, Otto “Colaboración a la Conferencia Nacional de la Vivienda Popular: Región de Los Lagos, Territorio de Neuquén” (1936).

\section{Fuentes secundarias}

\section{Libros}

Bandieri, Susana. Historia de la Patagonia. Buenos Aires: Sudamericana, 2005.

Bustillo, Ezequiel. El Despertar de Bariloche. Una estrategia patagónica. Buenos Aires: Editorial y Librería Goncourt, 1968.

De Agostini, Alberto. El Lanín. Parque Nacional. Buenos Aires: S.E., 1941. 
De Amador, F. Félix. Reseña histórica de San Martín de los Andes. San Martín de los Andes: Didot, 1998[1948].

Fortunato, Norberto. La civilización de las "tierras salvajes". Valores fundacionales del concepto de Parque Nacional. Buenos Aires: Prometeo Libros, 2010.

Frost, W. y Hall, C. M. (eds.) Tourism and National Parks: international perspectives on development, histories and change. London: Routledge, 2009.

Gingins, René, Lovato. María R. y Solanas, Stella M. San Martín de los Andes. Pueblo + Arquitectura. San Martín de los Andes: el autor, 2014.

Maragliano, M. Graciela. Hotel Lácar: 100 años en la vida de San Martín de los Andes. Córdoba: Ferreyra Editor, 2010.

Sánchez, Joan-Eugeni. Espacio, economía y sociedad. Barcelona: Siglo XXI, 1991.

\section{Capítulos de libro}

Almirón, Analía. "La dimensión espacial del turismo. Hacia una comprensión del turismo desde la espacialidad como construcción social de lugares", Espacio, espacialidad y multidisciplinariedad. Marta I. Kollman (coord.) Buenos Aires: Eudeba, 2011.

Almonacid, Fabián. "Comercio entre Chile y Argentina en la zona sur, en el contexto de una economía regional agropecuaria (1930-1960)". Pedro Navarro Floria, P y Walter Del Río (comp.) Cultura y espacio: Araucanía-Norpatagonia. Bariloche: Universidad Nacional de Rio Negro, Instituto de Investigaciones en Diversidad Cultural y Procesos de Cambio, 2011.

Aquín de Capiet, A. M. de las Nieves. "El Turismo. San Martín de los Andes se abre al país y al mundo", Comisión del Centenario y Fundación San Martín de los Andes, El libro del centenario de San Martín de los Andes. San Martín de los Andes: Publisher S.A., 1999.

Ballent, A. y Gorelik, A. "País urbano o país rural: la modernización territorial y su crisis". En Cattaruzza, Alejandro. Nueva Historia Argentina. Tomo VII, 145-200. Buenos Aires: Sudamericana, 2001.

Bandieri, Susana. "Actividades económicas y modalidades de asentamiento", Susana Bandieri, Orietta Favaro y Marta Morinelli (eds.) Historia de Neuquén. Buenos Aires: Plus Ultra, 1993. 147-261.

Bertoncello, Rodolfo. "Presentación", Turismo y geografía. Lugares y patrimonio natural-cultural de la Argentina, Rodolfo Bertoncello (comp.). Buenos Aires: Ciccus, 2008. 
Parques Nacionales y la configuración de un destino turístico: transformaciones socio...

Lolich, Liliana. "Los planes urbanos y su relación con el paisaje cultural en zonas de frontera. Caso Bariloche, Patagonia Argentina (1934-1979)", Paula Núñez (comp.) Miradas Transcordilleranas: Selección de Trabajos del IX Congreso Argentino Chileno de Estudios Históricos e Integración Cultural (San Carlos de Bariloche: IIDyPCa, UNRN-CONICET, 2011.

Méndez, Laura y Muñoz Sougarret, Jorge. “Alianzas sectoriales en clave regional. La Norpatagonia argentino-chilena entre 1895 y 1920", María Andrea Nicolletti y Paula Núñez (Comp.) Araucanía - Norpatagonia: la territorialidad en debate: perspectivas ambientales, culturales, sociales, políticas y económicas. Bariloche: Instituto de Investigaciones en Diversidad Cultural y Procesos de CambioCONICET-UNRN, 2013.

Nash, Roderick. "The American Invention of Natural Parks", American Quarterly. John Hopkins University Press: 1970. 726-735.

Polito Belmonte, Santiago. "Con el arribo del hombre blanco, 'las leyes se acatan, pero no se cumple'”, Comisión del Centenario y Fundación San Martín de los Andes El libro del centenario de San Martín de los Andes. San Martín de los Andes: Publisher S.A., 1999.

Pérez, Reyes Álvarez y Erra. "Economías mixtas de la Patagonia Nororiental Argentina y Centro y Sur de Chile" en Nicolletti, María Andrea y Núñez, Paula (Comp.) Araucanía - Norpatagonia: la territorialidad en debate: perspectivas ambientales, culturales, sociales, políticas y económicas. Instituto de Investigaciones en Diversidad Cultural y Procesos de Cambio-CONICET-UNRN, Bariloche, 2013.

Zusman, Perla "El paisaje: la razón y la emoción al servicio de la práctica turística", Rodolfo Bertoncello (comp) Turismo y geografía. Lugares y patrimonio naturalcultural de la Argentina Buenos Aires: Ciccus. 199-219.

\section{Artículos de revistas}

Bertoncello, Rodolfo. "Turismo y territorio. Otras prácticas, otras miradas", Aportes y transferencias, 6.2, (2002): 29-50.

Blanco, Graciela. "Las sociedades Anónimas cruzan los Andes: los inversores chilenos en Neuquén al comenzar el siglo XX", América Latina en la Historia Económica 2.38 (2012): 107-130.

Blodgett, Peter "Defining uncle Sam's playgrounds: Railroad advertising and the National Parks, 1917-1941” Historical Geography, 35 (2007): 80-113.

Capanegra, Alejandro. "El desarrollo turístico como estrategia política del Estado: de la política en turismo a la política turística. Argentina 1900-1975", Aportes y Transferencias. 14.1 (2010): 23-42. 
Diegues, A. C. "El mito moderno de la naturaleza intocada" Hombre y Ambiente 5758, Número Monográfico. Quito: Ediciones Abya Yala, 2000.

Disalver, Lary M. y Wyckoff, William. "The Political Geography of National Parks" Pacific Historical Review, 74. 2 (2005): 237-266.

Mallarach, Josep. "Parques Nacionales versus Reservas Indígenas en los Estados Unidos de América: un modelo en cuestión”, Ecología Política, 10 (1996): 25-34.

Núñez, Paula. Matossian, Brenda y Vejsbjerg, Laila "Patagonia, de margen exótico a periferia turística. Una mirada sobre un área natural protegida de frontera", PASOS Revista de Turismo y Patrimonio Cultural, 10. 1 (2012): 47-59.

Núñez, Paula. "La incompleta re-construcción peronista de la frontera: Un análisis desde la región del Nahuel Huapi, Argentina (1946-1955)" Estudios Fronterizos 16. 31 (2015): 91-116.

Ospital, M. Silvia. "Turismo y territorio nacional en Argentina. Actores sociales y políticas públicas, 1920-1940”, Estudios Interdisciplinarios de América Latina, 16.2 (2005): 63-84.

Pastoriza, Elisa y Piglia, Melina. "Asociaciones civiles, empresas y Estado en los orígenes del turismo argentino”, Anuario IEHS, 27 (2012): 393-415.

Piglia, Melina. "En torno a los Parques Nacionales: primeras experiencias de una política turística centralizada en la Argentina (1934-1950)”, PASOS Revista de Turismo y Patrimonio, 10.1 (2012): 61-73.

Scarzanella, Eugenia "Las bellezas naturales y la nación: los parques nacionales en Argentina en la primera mitad del siglo XX", Revista Europea de Estudios Latinoamericanos y del Caribe, 73 (2002): 5-21.

\section{Tesis, documentos, ponencias y otros inéditos}

Masotta, Carlos. "Un Desierto para la Nación. La Patagonia en las Narraciones del Estado de la Concordancia (1932-1943)", (IV Congreso Chileno de Antropología. Colegio de Antropólogos de Chile A. G, Santiago de Chile, 2001)

Navarro Floria, Pedro. "El proceso de construcción social de la región del Nahuel Huapi en la práctica simbólica y material de Exequiel Bustillo (1934-1944)", Revista Pilquén, Sección Ciencias Sociales, IX.9, 2008.

Navarro Floria, Pedro. "La "Suiza argentina", de utopía agraria a postal turística: la resignificación de un espacio entre los siglos XIX y XX". 3eras Jornadas de Historia de la Patagonia. San Carlos de Bariloche, noviembre 2008. 
Parques Nacionales y la configuración de un destino turístico: transformaciones socio...

Núñez, Paula. "Naturaleza construida. Una revisión sobre la interpretación del paisaje en la zona del Nahuel Huapi". 3eras Jornadas de Historia de la Patagonia. San Carlos de Bariloche, noviembre 2008.

Vejsbjerg, Laila. "Turismo, conservación y políticas públicas en espacios de frontera. El rol de los parques nacionales en la Norpatagonia andina argentina (1916-1976)". VII Simposio Internacional y XII Jornadas Nacionales de Investigación - Acción en Turismo CONDET. Facultd de Turismo, UNCo, Neuquén, octubre 2015. 